\title{
ESTADO Y DESARROLLO EN LOS DISCURSOS DEL BANCO
}

\author{
MUNDIAL* \\ Víctor Ramiro Fernández
María Cecilia Güemes
José Ignacio Vigil****
}

Fecha de recepción: 3 de octubre de 2005. Fecha de aceptación: 5 de diciembre de 2005.

\section{Resumen}

Centrado en un análisis acerca del papel otorgado por el Banco Mundial al Estado en los procesos de desarrollo a partir de los años noventa, el trabajo destaca la notable continuidad exhibida por las propuestas del вм de desimplicar al Estado de los procesos productivoindustriales. Además, fundados en la experiencia argentina de los noventa, se presentan evidencias de dos claras inconsistencias mostradas por las politicas inspiradas en dicha continuidad: a) el constante crecimiento del Estado a partir de reformas paradójicamente orientadas hacia su reducción; b) el vaciamiento de las estructuras y capacidades estatales del área productivo-industrial, cuya existencia el BM demanda como condición para habilitar políticas industriales complejas. Por último, se aborda el escenario latinoamericano para reflexionar acerca de cómo las mencionadas inconsistencias contribuyen a explicar el retroceso estructural de la región en el contexto global.

Palabras claves: Estado, desarrollo, Banco Mundial, América Latina, Argentina.

\footnotetext{
* Parte de una investigación sobre "Capacidades estatales, dinámica productivo industrial y desarrollo regional. en la Provincia de Santa Fe, Argentina" que llevan adelante los autores en la Universidad Nacional del Litoral.

** Profesor-investigador del Consejo Nacional de Investigaciones Científicas y Tecnológicas (CONICET) Universidad Nacional del Litoral, Santa Fe-Argentina. Correo electrónico: rfernad@fcjs.unl.edu.ar

****Profesora-investigadora, Universidad Nacional del Litoral. Correo electrónico: ceciliaguemes@gmail.com

***** Profesor investigador, Universidad Nacional del Litoral. Correo electrónico: jvigil@fiete.org.ar
} 


\section{Abstract}

Focusing on an analysis of the role provided to the State by the World Bank in development processes since the 1990s, this paper emphasizes the noteworthy continuity exhibited by the $W B$ 's proposals to separate the State from any involvement in industrial production processes. Based on Argentina's experience in the 1990s, evidence is also presented of two clear inconsistencies shown by policies inspired by such continuity: a) the constant growth of the State starting with the reforms that were paradoxically oriented towards its reduction; b) the emptying of state structures and capacities in the industrial production area, whose existence the WB demands as a condition for enabling complex industrial policies. Finally, it deals with the Latin American scenario to reflect on how the mentioned inconsistencies contribute to and explain structural reversal in the region in a global context.

Key words: State, development, World Bank, Latin America, Argentina.

\section{Résumé}

Centré sur une analyse sur le rôle octroyé par la Banque Mondiale à l'Etat dans les processus de développement à partir des années 90, ce travail souligne la notable continuité démontrée par les propositions de la BM de désimpliquer l'Etat des processus productifs-industriels. En plus, se basant sur l'expérience argentine des années 90, on dégage deux claires inconsistances montrées par les politiques inspirées sur la dite continuité: a) la croissance constante de l'Etat à partir de réformes paradoxalement orientées vers sa réduction; b) le vide progressif des structures et des capacités de l'Etat dans le domaine productif-industriel, dont l'existence est exigée par la вм comme condition pour habiliter des politiques industrielles complexes. Finalement, on aborde le scénario latino-américain pour réfléchir sur comment ces inconsistances contribuent à expliquer le recul structurel de la région dans le contexte global. Mots-cléfs: Etat, développement, Banque Mondiale, Amérique Latine, Argentina.

\section{Resumo}

Centrado num análise sobre o papel cedido pelo Banco Mundial ao Estado nos processos de desenvolvimento a partir dos anos 90, o trabalho destaca a notável continuidade exibida pelas propostas do bm de desimplicar o Estado dos processos produtivo-industriais. Além, baseados na experiência argentina dos anos 90, aprsentam-se evidências das duas claras inconsitências evidenciadas pelas políticas inspiradas em tal continuidade: a) o constante crescimento do Estado a partir das reformas paradoxicamte orientadas à sua diminuição; b) o esvaziamento das estruturas e capacidades estaduais da área produtivo-industrial, cuja existência o bm exige como condição para a habilitação de políticas industriais complexas. Por último, aborda-se o cenário da América Latina para refletir sobre como é que as mencionadas inconsistências contribuem para a explicação do retrocesso estrutural da região no contexto global.

Palavras chave: Estado, desenvolvimento, Banco Mundial, América Latina, Argentina. 


\section{Introducción}

$\mathrm{E}$

1 presente trabajo tiene como punto de partida un análisis del tratamiento dado por el Banco Mundial (BM; wB, por sus siglas en inglés) al Estado como motor del desarrollo a lo largo de la década de los noventa. Nuestro objetivo, a partir de dicho análisis, es doble: primero, intentamos detectar importantes inconsistencias en el discurso del organismo acerca del papel del Estado en el desarrollo al momento de materializarse en políticas públicas y, segundo, reflexionar sobre los efectos que dichas inconsistencias acarrean tanto a las estructuras mismas del Estado, como en los procesos de desarrollo que tienen lugar en los países que han seguido las líneas de reformas trazadas por el вм.

La plataforma inicial de este artículo se construye a partir de la identificación de un aspecto clave: las ideas sustentadas a lo largo de los noventa por el Banco Mundial, aun cuando parecieron marcar un cambio de rumbo respecto de sus propias e iniciales posturas en cuanto a la relación Estado-desarrollo, trabajaron sobre la base de una marcada continuidad, expresada en la subordinación de ciertas ideas a las reformas de primera generación, cuyos ejes centrales buscaban reinstalar el dominio de los mecanismos de mercado y, concomitantemente, desplazar de forma sistemática al Estado de sus funciones de motor directo del proceso productivo industrial.

A partir de dicha continuidad, el discurso del BM en relación con el Estado inspiró políticas públicas que dieron lugar a dos inconsistencias que impactaron directamente las estructuras de los estados involucrados: la primera, se vincula con la demanda de reducción del tamaño y la implicación del Estado muy presente en las reformas estructurales recomendadas a inicios de los noventa y el paradójico crecimiento del Estado, asociado al aumento de la desigualdad y de la exclusión social que acompañó a dichas reformas. La segunda se relaciona con el requerimiento presentado por el вм hacia fines de los noventa de contar con capacidades institucionales previas para el desarrollo de políticas productivoindustriales, en un escenario donde las capacidades aparecen debilitadas por las reformas estructurales de inicio de la mencionada década.

Para la constatación de dichas inconsistencias apelamos a un estudio de caso, a partir del análisis de lo acontecido en Argentina durante los noventa, en lo que fuera una de las experiencias más claramente alineadas con las propuestas de los organismos de financiamiento internacional (OFI). Dentro del caso argentino, y atento a la relevancia cuantitativa y cualitativa asumida en ese mismo tiempo por el nivel regional, damos un tratamiento específico a la provincia de Santa Fe, la cual, además de constituir la segunda 
del país en términos económicos y demográficos, se ha destacado por su ciclo de crecimiento y su prolijo seguimiento de las pautas de sanidad fiscal sugeridas por el BM.

Nuestro propósito no sólo consiste en remarcar y constatar empíricamente las inconsistencias del discurso del вм - expresadas en las políticas que siguieron sus recomendaciones-, sino que, como segundo objetivo, procuramos dar cuenta de sus efectos. Para ello, salimos del caso argentino para tomar una perspectiva latinoamericana, en la cual —más allá de ciertas especificidades nacionales - operó el espíritu de reformas impulsadas desde el BM. Procuramos entonces examinar esos efectos a partir de un análisis comparado del comportamiento del desarrollo de la región (el cual incluye crecimiento, inserción externa y cohesión interna) respecto de aquella exhibida por los países asiáticos que tomaron distancia de la propuesta de los OFI — y el BM-, especialmente en lo relacionado con el tratamiento dado al Estado como motor del desarrollo.

Desde el contraste — claramente desfavorable para América Latina (AL) - concluimos con una demanda dirigida no sólo a la autocrítica del Bм respecto de sus contradictorias e inconsistentes posiciones en relación con el Estado en el desarrollo, sino y, fundamentalmente, a los propios países en desarrollo - especialmente los latinoamericanos- para encarar una estrategia de desarrollo endógena, fundada en la capacidad estatal y el respeto de las especificidades nacionales nunca atendidas por los proyectos uniformes de los OFI.

\section{Del Estado como problema al Estado como solución. ${ }^{1}$}

\section{Los documentos del Banco Mundial en la década de los noventa}

Una observación superficial de los documentos del Bм de los noventa sugiere que existieron dos posturas acerca del papel que debe cumplir el Estado en el proceso de desarrollo: a) una que sostuvo que el Estado y su intervención constituyen fundamentalmente un problema para alcanzar el desarrollo, y la cual tiene raíces en documentos aparecidos a comienzos de esa década; y b) otra, más reciente, que lo plantea como una solución. Sin embargo, una exploración atenta muestra una línea clara de continuidad que liga una y otra postura o, mejor dicho, que marca la subordinación de la segunda a los postulados centrales de la primera. Dicha línea, con enfoques aparentemente opuestos, se expresa en la común marginación a la cual son sometidas las áreas del Estado vinculadas con los procesos productivos y, por medio de ello, con las fuertes restricciones que desde ambas perspectivas se plantean a la formulación estatal de políticas industriales endógenas.

Mediante el examen de esos enfoques y la determinación de esa línea de continuidad, es posible encontrar respuestas a los siguientes interrogantes que guiarán nuestro argumento: ¿cuál ha sido la posición del BM respecto del papel del Estado en la motorización

En referencia a The States as Problem and Solution. Predation, Embedded autonomy and Adjustment, de Evans (1992). 
del desarrollo en los noventa? ¿En qué medida esa postura ha ido variando? Finalmente, en ese marco de aparentes variaciones, ¿qué consecuencias tuvo la traducción del discurso al plano de las políticas públicas en aquellos países que han adoptado la estrategia del BM?

\section{El Estado como problema}

Hacia 1991 el Banco Mundial inició un camino de revisión de la problemática del desarrollo. En ese contexto emergió y se fue consolidando una ofensiva reorientadora fundada en una crítica del organismo a los resultados obtenidos por los enfoques de matriz keynesiana sostenidos en la etapa de posguerra, fundamentalmente en los aspectos vinculados a la intervención del Estado (wB, 1991a:4). Una de las líneas centrales de dicha ofensiva, traducida en las recomendaciones dadas a los países receptores de su financiamiento, fue la insistencia en el desplazamiento de la fe en el Estado como actor estratégico del desarrollo y el agresivo impulso de una mayor confianza en la capacidad dinamizadora del mercado. ${ }^{2}$ Es decir, el Estado pasó a ser visto ya no como un instrumento fundamental para promover el desarrollo, sino como un problema u obstáculo para su generación.

Las primeras manifestaciones concretas de esa orientación ya comenzaron a materializarse incipientemente en el informe de 1987, en el cual el BM afirmó, con argumentación propicia a la libertad de mercado, que el problema de los países en desarrollo era la debilidad del ambiente favorable al crecimiento del sector privado y la falta de políticas tendientes a ello, remarcando que el papel de los gobiernos debe ser el de corrector de las fallas del mercado (wB, 1987). Posteriormente, en el informe de 1989, referido a sistemas financieros, se dio continuidad a esa línea argumental, destacando la necesidad de profundizar la desregulación de los mercados financieros y, en el mismo sendero, el de 1991 adoptó la frase market friendly (políticas amistosas con el mercado), transformada luego en casi un concepto icono de la vía del desarrollo promovida por el BM. En torno de dicho término se destacaba que el mejor método para producir y distribuir bienes y servicios eficientemente consistía en un mercado que funciona en régimen de competencia — externa e interna- (wB, 1991:1), en el cual la función económica del Estado es focalizarse en definir y proteger los derechos de propiedad, establecer sistemas jurídicos y normativos eficaces, mejorar el desempeño de la administración pública e, incluso, proteger el medio ambiente. De esa manera, en esta aparente "armonía con el mercado", las políticas "amistosas" del Estado debían consistir en hacer el "entorno" más favorable al capital privado (wB, 1991, capítulo 4).

Con este planteamiento, el BM concluyó que "es mejor no pedir al gobierno que dirija minuciosamente el desarrollo" (wB, 1991, capítulo 2), asumiendo, a partir de ello, una

Trabajos como los de Balassa et al. (1982) y Lal (1983) jugaron un papel relevante en la (re)instalación de las raíces del pensamiento neoliberal en los ofI y, lógicamente, en el BM. 
reinterpretación del funcionamiento del Estado, que conducía a reconsiderar las relaciones entre el sistema político y la política económica (wB, 1991, capítulo 7). Esa reconsideración quedó estructurada con base en dos grandes ejes, que buscaban articular la imperante lectura de las "fallas del Estado" con una muy moderada admisión de las "fallas del mercado".

Así, en relación con el primer eje, el вм estableció que la intervención estatal generalmente está impregnada de objetivos políticos, no económicos, y por ello suele ser perjudicial, ya que alimenta comportamientos del tipo "buscadores de rentas" (wB, 1991, capítulo 7), y esto, a su vez, provoca una continua expansión del Estado (no por demanda de bienes colectivos, sino por satisfacción de prebendas). En línea con los planteamientos de la Public Choice (Escuela de la Elección Pública), la estrategia para escapar de este comportamiento propuesto por el вм consistió en reemplazar el control burocrático por mecanismos de mercado, aplicando los instrumentos de la optimización individual hacia el interior del Estado para reducirlo (wB, 1991).

Respecto del segundo eje, se instaló la idea de la necesaria reconstrucción del Estado para la formulación de políticas "amistosas con el mercado". Ello implicó para el BM el reconocimiento de que, en ciertos sectores y para ciertas funciones, los mercados podían actuar en forma ineficiente y, en su virtud, la intervención del Estado permitiría que la economía cristalice todas sus posibilidades (wB, 1991, capítulo 7). Este argumento habilitaba entonces una intervención selectiva (contenida y responsable) en aquellas áreas en las cuales se constatara claramente que el mercado tenía una "asignación deficiente" (wB, 1991, capítulo 8). ${ }^{3}$

Sin embargo, esta plataforma teórica del Bм, constituida alrededor del concepto discursivo armonía del mercado, el cual admitía una intervención estatal muy controlada y selectiva, fundada en la noción de "falla de mercado", fue acompañada por el sistemático desplazamiento del Estado de las áreas fundamentales de coordinación del sector productivo y su relegamiento al papel de proveedor del marco regulador favorable a la competencia. Efectivamente, con la premisa de que el Estado se presentaba en esa área como un problema para alcanzar el desarrollo, la consideración de la política industrial y, en general, toda aquella ligada al apoyo del sector productivo fue erradicada del discurso del Bм y sus políticas públicas recomendadas para los países en desarrollo durante la década de los noventa.

Valiéndose de su presentación como institución apolítica, el BM, a la vez que encontró fundamentos para desplazar las estructuras y recursos comprometidos en la coordinación y motorización del sector productivo-industrial, viabilizó la aplicación de la política

3 Específicamente, el вм consideró que el Estado puede actuar eventualmente y en ciertas circunstancias en salud pública, educación, infraestructura, organización normativa y administrativa, además del cuidado del medio ambiente. 
neoclásica de apertura comercial, utilizando al Estado sólo como una "correa de transmisión" entre las realidades de las economías internacional y las nacionales (Wade, 1990).

Asimismo, el desplazamiento del Estado de las áreas productivo-industriales y la consolidación de la plataforma market friendly, encontraron respaldo en muchos de los desarrollos académicos vinculados al análisis del proceso de globalización. Estos últimos, tanto en sus manifestaciones radicales, como en las más moderadas, destacan que los procesos de producción y de intercambio tienen lugar dentro de redes ya no organizadas nacional, sino globalmente, por lo cual a los estados, en un medio en el que su autonomía y su control sobre las economías nacionales van quedando cada vez más disminuidas, ${ }^{4}$ sólo les cabe tratar de hacer más atractivos sus territorios a la inversión extranjera.

Además, es necesario destacar que la despreocupación por el papel del Estado en el pensamiento del BM se manifestó ya no sólo en los documentos de inicio de la década, pues trabajos posteriores del organismo estuvieron lejos de colocarlo como actor estratégico, y mucho menos plantearon como un campo de observación futura la intervención del Estado en el proceso productivo. De hecho, entre 1994 y 1996 los informes del BM reafirmaron las funciones subsidiarias y subordinadas que le corresponden al Estado en relación con el mercado.

En síntesis, toda la plataforma teórica desarrollada por la ofensiva del вм desde fines de los ochenta y principios, e incluso mediados, de los noventa puede ser presentada mediante tres ejes centrales:

Primero, la redefinición de la relación entre las instituciones políticas y las de política económica posicionó rezagadamente al Estado respecto del mercado, convirtiendo a este último en el mecanismo privilegiado en la regulación de las transacciones económicas, así como en la contención del principal problema diagnosticado por el BM, la expansión del tamaño y la intervención estatal. Para ello, el Bм auspició una serie de programas de privatizaciones y desregulaciones tendientes al desplazamiento de sus funciones empresariales y regulativas como condición para acceder al crédito. Segundo, dentro del objetivo de reducir el tamaño y las funciones del Estado, se le reconoció a este último cierto campo de actuación restringido en áreas de educación, salud e infraestructura, ante la posible presencia de "fallas de mercado". Finalmente, y como consecuencia de lo anterior, hubo un claro desplazamiento del Estado en lo que respecta a la planificación, orientación y promoción directa de los procesos productivos.

Entre los escépticos de la globalización, Camilleri y Falk (1992) y Ohmae (1995); y en cuanto a los moderados, Strange (1996) y Cox (1997). 


\section{El Estado como solución}

Hacia 1997, mediante el Informe sobre el Desarrollo Mundial (IDM, 1997), el BM experimentó un aparente viraje en relación con su postura anterior, la cual veía al Estado como problema, colocando su existencia y calidad como factor fundamental para pensar el desarrollo. Inscrito en lo que los propios organismos comenzaron a denominar reformas de segunda generación, dicho informe pasó a exaltar el papel de las calidades institucionales en la obtención de una administración pública moderna, descentralizada, transparente y con capacidad reguladora (BM, 1997:3-4). Ahora bien, ¿implicó este documento un cambio efectivo respecto de aquella idea manifestada desde comienzos de los noventa, caracterizada por la sistemática desimplicación del actor estatal del proceso productivo?

En verdad, la necesidad de considerar al Estado como solución comenzó algunos años antes, lo que exige una breve mirada retrospectiva. Hacia 1992-1993 el вм se introdujo en la consideración de algunas experiencias de política económica industrial que venían teniendo lugar en el este asiático, replanteando allí el debate del Estado como "originador" de problemas y como "motorizador del desarrollo productivo". Sirvió de preámbulo una serie de trabajos con importante base empírica, que asociaban los exitosos resultados de algunas economías de dicha región con la fuerte presencia del Estado en la orientación de políticas industriales (Amsden, 1989; Wade, 1990; Weiss, 1998). Ello coincidió con la intención de Japón de, por un lado, aumentar hacia el interior del Bм su capacidad de influencia ideológica en temas de desarrollo y asimilarla a su capacidad financiera (Wade, 1997) y, por otro, expandir en el nivel regional la presencia de su modelo que, por medio de una activa mediación del actor estatal con altas capacidades (Johnson, 1982; Aoki, 1988), le permitió contar con una estructura económico-institucional con fuerte integración interna, orientada hacia el mercado externo.

De esa forma, un cúmulo de trabajos académicos asociados al creciente peso económico de los países de la región fueron mostrando una estrategia de inserción internacional que colocó al Estado en el centro del escenario, situándose con ello en la vereda de enfrente a la posición del mainstream (corriente principal). Sin embargo, y paradójicamente, la inserción exitosa del este asiático en el mercado global fue destacada por el cuerpo académico neoliberal para marcar el contraste entre una economía cerrada (Latinoamérica) y una de mercado abierta al mundo (este asiático) (Balassa, 1982), desacreditando el papel de "palanca motorizadora del desarrollo" asignado al Estado por los trabajos antes citados. Con ese argumento, aterrizó el shock de reformas y ajuste neoliberales de comienzos de los noventa en Latinoamérica, el cual, sin la obtención de los resultados esperados (sobre todo en el plano social), dio pie a la consideración de las condiciones institucionales en las que ha buceado el pensamiento del Bм desde 1997 (IDM, 1997).

No obstante, a pesar de esa primera reacción (restauradora neoliberal), la presencia de hechos robustos, difundidos académicamente a partir de medios analíticos alternativos a 
los del mainstream, pareció ganar finalmente un lugar en el análisis y las propuestas del BM, inspirando una reconocida y recordada publicación: El milagro del este asiático: crecimiento económico y política pública (wB, 1993). ${ }^{5}$ Éste planteó graves interrogantes al enfoque anterior (el Estado como problema) sustentado por el Banco en las relaciones entre el Estado, el sector privado y el mercado. En tal sentido, desde la admisión del éxito de algunos países como Japón, Corea, Singapur y Taiwán, pasó a considerarse el papel relevante de una serie de políticas destinadas a la promoción industrial, ausentes en los documentos anteriores. De hecho, El milagro del este asiático fue el primero de los textos importantes del Banco que reconoció que, en la mayoría de los países de esa región, la búsqueda del crecimiento y la mejora en la inserción económica internacional estuvieron acompañadas de una amplia y sistemática intervención del Estado (wB, 1993, capítulos 2 y 3$)$.

Sin embargo, el documento colocó fuertes reparos a la introducción de la intervención estatal como herramienta de desarrollo, señalando que, en la analizada experiencia asiática, las intervenciones habían funcionado porque no fueron excesivas y respondían a condiciones institucionales y económicas específicas (wB, 1993, capítulo 4), por lo cual, no habiendo mostrando posibilidad de éxito en otros contextos, no eran recomendables indiscriminadamente (wB, 1993). Asimismo, asumiendo una asombrosa actitud contrafáctica, el BM sostuvo en el transcurso del documento que no pueden establecerse relaciones de causalidad directa entre el crecimiento económico obtenido y la intervención selectiva, ya que no puede saberse qué hubiese pasado de no haberse producido la intervención mencionada (Amsden, 1994).

Por tanto, lo que a prima facie parecía un viraje hacia un enfoque que reconocía la relevancia de incorporar la acción del Estado a la motorización del desarrollo y la promoción del sector productivo, en realidad se convirtió en una continuidad respecto del primero. Más allá de transformarse inicialmente en una promisoria apertura del debate acerca de las relaciones entre política pública y crecimiento económico, la postura final asumida por el BM (1993) terminó acomodando la lectura de las experiencias analizadas a una confirmación de la dominante visión market friendly y sosteniendo que el este asiático constituía un “caso especial" y, por ello, no reproducible en la generalidad de los países (wB, 1993).

Ahora bien, posterior al documento de 1993, la aparición de una serie de trabajos acerca de las experiencias del este asiático que destacaban las sólidas capacidades de las estructuras estatales de las áreas de la acumulación para producir el desarrollo (Evans, 1995), sumado a los crecientes problemas en el campo social que acompañaron en el

5 El documento es un estudio comparado de ocho economías del este asiático: los cuatro tigres; y las nuevas economías industrializadas que, lideradas por Japón, constituyen las HPAE (hight performing asian economies). 
escenario latinoamericano las reformas neoliberales, parecieron dar legitimidad a una rediscusión acerca del papel del Estado en la conducción del proceso de desarrollo.

Posiblemente, como resultado de ello, se puso al Estado en el centro de la escena del desarrollo y la apelación a la consideración de las calidades institucionales que del informe de 1997 surgían, daban pie a entender que existía una aproximación a la discusión del Estado como solución. Sin embargo, una vez más, el aparente viraje se tradujo en continuidad respecto de las premisas centrales del primer enfoque, el cual sostenía la necesidad de mantener contenido al Estado ante los riesgos de que actuara como problematizador del desarrollo. Mostramos tres elementos explicativos de esa continuidad.

En primer lugar, una característica remarcable de las reformas de segunda generación en las cuales se inspiraron las demandas de capacidades institucionales fue que se formularon en un marco de subordinación a la propuesta de aquel primer enfoque. En tal sentido, atento a que la generación de capacidades institucionales se reconocen lentas y demandan tiempo (вм, 1997, capítulo 5), ${ }^{6}$ el BM explicitó la necesidad de reforzar esa capacidad en aquellas funciones dedicadas a otorgar un marco institucional favorable a la inversión privada, a partir de la estabilidad macroeconómica, la no distorsión de precios y una liberalización del comercio y de las inversiones (BM, IDM, 1997).

En segundo lugar, mientras el informe extendió la consideración del papel de las capacidades a un amplio campo de materias, como el ordenamiento jurídico, la protección de los grupos sociales más vulnerables, la inversión en infraestructura y, en ciertas circunstancias, la salud y la educación (BM, 1997, capítulo 3); lo cierto es que, en el marco de esa generalidad, el campo de las capacidades estatales ligadas a las políticas productivo-industriales estuvo lejos de ocupar un lugar relevante. De hecho, la referencia a la política industrial fue escasamente considerada en el capítulo 4 de la parte II, con pocas y difusas referencias a casos aislados (BM, IDM, 1997, capítulo 4). ${ }^{7}$

En tercer lugar, dentro de ese escueto tratamiento, el вм le aplicó al campo de las políticas productivo-industriales la fórmula que domina el documento: los estados deben hacer sólo aquello que son capaces de hacer (acomodando sus funciones a sus capacidades), reclamando como requisitos indispensables para el desarrollo de políticas industriales complejas la presencia —o construcción previa— de instituciones estatales con altas capacidades (BM, IDM, 1997, capítulo 3). Respetando esa premisa, el BM estableció que, entre quienes no han sabido construir instituciones fuertes, la privatización y la liberaliza-

$6 \quad$ El BM menciona que pueden tomarse medidas como la introducción de la competencia al interior del Estado con resultados mas rápidos que la construcción de una burocracia capaz y competente (BM, IDM, 1997, capítulo 5).

7 En sólo tres páginas se describe apenas tres campos de acción: a) "coordinación de inversiones"; b) "fortalecimiento de redes"; y c) "sustitución de mercados"; y se sostiene que en aquellos casos en los cuales se propongan políticas industriales complejas (caso de ay c) "se deben abordar con cautela o no deben abordarse en absoluto" (BM, IDM, 1997:86); las que requieren una ligera intervención $($ caso $b$ ) podrían ejecutarse, dado que el costo de su fracaso es bajo. 
ción serán las opciones más indicadas si existen gobiernos hipertrofiados y sobrecargados (BM, IDM, 1997, capítulo 4). Es decir, el BM subordinó la implicación del Estado en el campo productivo industrial al seguimiento previo de las reformas privatizadoras y desreguladoras impulsadas desde inicios de los noventa.

En síntesis, el tratamiento dado por el вм a la reconvocatoria al Estado y sus capacidades, efectuado en el Informe de 1997, no emergió como un elemento destinado a cambiar cualitativamente las ideas imperantes desde 1990, es decir, no introdujo al Estado dentro de un viraje discursivo orientado a la motorización del sector productivo industrial, sino que quedó planteado como un ejercicio de adaptabilidad, en el que —al igual que sucedió con el milagro del este asiático - campeó finalmente una notable continuidad con las reformas market friendly presentes en la plataforma teórica de inicios de los noventa, así como una funcionalización del problema de la capacidad estatal y la calidad institucional a los programas de ajuste estructural impulsados desde esa plataforma.

Por lo tanto, a aquellos países en desarrollo que pudieran pretender capitalizar el IDM de 1997 para asociar la reintroducción del Estado con el desarrollo de políticas productivoindustriales, el BM les sube el listón, planteándoles que para ingresar a este campo de acción se requieren calidades difícilmente encontrables en estados que han hecho del desmantelamiento de las estructuras vinculadas a la producción y la industria el eje de reformas a las políticas sustitutivas promovidas durante las décadas de los ochenta y noventa. Una consecuencia directa de ello es que el argumento de las capacidades y calidades institucionales difundido por el BM terminó transformándose en elemento disuasor para aquellos países interesados en implicar al Estado directamente en las políticas de desarrollo productivo.

\section{Consecuencias de la continuidad discursiva \\ del BM: descubriendo las inconsistencias en la traducción a las políticas públicas}

Hasta aquí vimos que, no obstante haber presentado dos enfoques aparentemente diferentes en relación con el papel del Estado en el desarrollo, el BM mostró a lo largo de la década de 1990 una línea de continuidad anclada en una plataforma que da prioridad a la capacidad autorreguladora del mercado y su poder para generar equilibrios económicos y sociales, desplazando al Estado de su injerencia en el impulso y coordinación de los procesos productivos. Dejamos, por lo tanto, claramente establecido que lo que parecían ser dos puntas de dos ovillos diferentes, en realidad terminaron siendo principio y fin de uno solo. Ahora bien, como adelantamos inicialmente, sobre esa línea de continuidad se fueron conformando - a partir de su traducción en políticas públicas — dos inconsistencias básicas.

Por un lado, hubo un constante estímulo en las reformas del вм hacia el downsizing estatal (reducción del Estado), cuyos efectos económico-sociales — desempleo, subempleo 
y desigualdad social — se han vuelto sobre el Estado en forma de demandas de bienes públicos, incrementando paradójicamente su volumen e implicación. Por otro lado, el BM exige altas capacidades estatales en el campo productivo como precondición para el desarrollo de políticas exitosas. Sin embargo, la ausencia de capacidades, que aquí aparece como un justificativo de la reapelación al enfoque neoliberal, puede atribuirse en gran medida a la serie inicial de ajuste estructural que ha dejado vacías las áreas estatales dedicadas a la promoción industrial. Sintéticamente, fruto de la desimplicación estatal comenzada en las reformas de primera generación, se profundizaron las debilidades de las capacidades reclamadas en las de segunda generación.

Ahora bien, ¿cómo es posible dar cuenta empíricamente de esas relaciones entre la continuidad y las inconsistencias del BM en su visión acerca del papel del Estado en el proceso de desarrollo? ¿En qué medida podemos ver dichas inconsistencias en el escenario latinoamericano?

\section{Las ideas del Banco Mundial y su ingreso}

a Argentina: la traducción en politicas de ajuste

estructural en los niveles macro y meso

La elección del escenario latinoamericano como campo de análisis de las ideas y políticas recomendadas por el вм encuentra fundamento en el protagonismo asumido por la región en la implantación de programas de reformas inspirados en el Consenso de Washington desde fines de años ochenta, a partir del colapso del modelo de sustitución de importaciones. Dentro de ello, creemos pertinente la adopción del caso argentino dada su conversión en poster child $^{8}$ en la instrumentación de ese cuerpo de recomendaciones del вм.

Efectivamente, acompañándose por enfoques vernáculos que apoyaban e inspiraban la reestructuración, Argentina se acopló al discurso hegemónico que proponía el establecimiento de las políticas públicas conocidas como reformas de primera generación, destinadas a imponer el achicamiento y el retiro estatal en ciertas áreas estratégicas, como la industrial, y avanzar en el desmantelamiento de la "matriz de reproducción estado-céntrica" (Cavarozzi, 1996) crecida a la luz de las estrategias sustitutivas.

A fines de los ochenta, y con mayor firmeza a lo largo de los noventa, el gobierno argentino emprendió una agresiva estrategia de reformas estructurales — que en muchos aspectos continuaba la intentada por la dictadura militar en la segunda mitad de los setenta-, cuya meta principal era recomponer las finanzas públicas, a partir de la reestructuración y reducción del Estado mediante una fuerte restricción de gastos y el traspaso de funciones del Estado nacional hacia gobiernos subnacionales, así como un proceso de reformas

$8 \quad$ Expresión utilizada por Evans (2004:35). 
administrativas estructurado a partir de la desregulación y un muy importante programa de privatizaciones (Rojo y Canosa, 1992:33; Domenicone et al., 1992).

En esa línea de reformas, se suspendieron los subsidios a la industria y se les reemplazó por un programa de crédito impositivo, más estricto y controlado (ley de emergencia, julio de 1989) que, no obstante estar destinado a mejor monitoreo en su uso, tenía un claro objetivo de reducción del costo fiscal.

Este plan de austeridad fiscal y reducción del Estado se insertó, a su vez, en una estrategia macroeconómica fundada en un modelo de "caja de convertibilidad" y apertura comercial y financiera, con lo cual se pretendía, mediante la incorporación de nuevas tecnologías asociada al ingreso de capitales, modernizar el sistema productivo y cualificar la inserción internacional generadora de divisas (Llach, 1997).

Mientras el gobierno argentino llevaba adelante esa estrategia, los organismos de financiamiento internacional, al colocar al país como alumno modelo, prestaban pleno apoyo a las reformas. ${ }^{9}$ El Banco Mundial, por su parte, alentando acciones profundizadoras, indicaba en su Informe "Argentina, from insolvency to Growth" (1993) la relevancia de trabajar en medidas ligadas a reformas administrativas, reestructuración burocrática, reformas en la seguridad social y un sistema de coparticipación federal; es decir, en toda una serie de transformaciones guiadas por un criterio estrechamente fiscalista de reducción de gastos y aumento de ingresos en el sector público. ${ }^{10}$

Ahora bien, ¿en qué medida estas reformas profundas, las cuales encontraban cobertura en los desarrollos teóricos del BM, fueron capaces de cumplir con los dos objetivos clave que se propusieron tanto a principios, como finales de los años los noventa: la reducción del tamaño y campo de acción del Estado, y el fortalecimiento de sus capacidades?

\section{Los limites en la reducción del tamaño del Estado, fuentes de una primera inconsistencia}

La primera respuesta a ese interrogante es que, tal como se aprecia en la Gráfica 1, en la experiencia argentina, no obstante haber sido el downsizing (por medio del saneamiento financiero y austeridad fiscal) uno de los objetivos centrales de las reformas, se verificó un incremento del gasto público per capita en el nivel nacional en toda la década de los noventa.

Atentos a ese comportamiento, ¿cuáles son los argumentos discursivos que explican esta continua y creciente expansión del Estado y, por consiguiente, el incumplimiento de los objetivos de los planes de reforma y ajuste?

$9 \quad$ El apoyo del BM y el BID a los procesos de reformas del sector público en Argentina no sólo se vertieron en documentos, sino en la aprobación y concesión de cuantiosos recursos (Domenicone et al., 1992:23).

10 El informe del BM acerca de Argentina establecía que "el traspaso de la educación secundaria a las pro vincias debería facilitar el achicamiento o aun el cierre del Ministerio de Educación” (BM, 1993:xxxviii). 


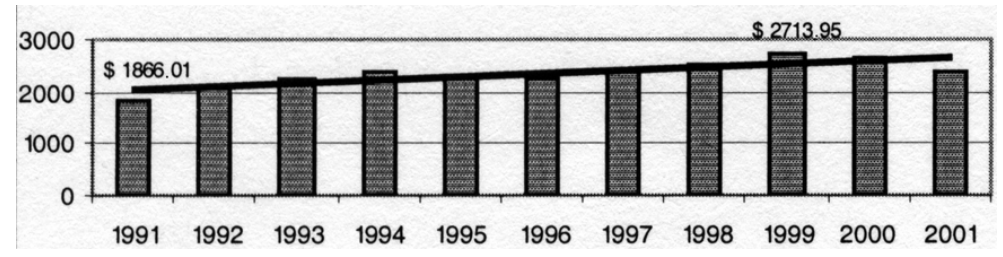

Gráfica 1. Evolución del gasto público total per capita (nacional, provincial y GCBA).

Fuente: elaboración propia con base en datos de la Dirección de Gastos Sociales Consolidados, Secretaría de Política Económica, Ministerio de Economía y Producción (MECON).

\section{En busca de interpretaciones respecto de la expansión del Estado}

Una primera línea de análisis fue sostenida por quienes, desde el interior del Estado, problematizan su crecimiento afirmando que, si los planes de ajuste, reestructuración y racionalización que reunían las ideas remercantilizadoras del denominado Consenso de Washington no lograron los resultados deseados, fue porque las reformas no se profundizaron lo suficiente. ${ }^{11}$

Esta interpretación, que encaja en el posicionamiento asumido por el Banco Mundial, responde a una línea argumental que, utilizando instrumental teórico neoclásico y, más específicamente, los aportes de la escuela del Public Choice,${ }^{12}$ considera al sistema económico como un espacio constituido a partir de la libre operación de los individuos en un mercado cuyos mecanismos tienden al equilibrio. La intervención de un agente externo a dicho mercado, como el Estado, actuando con lógicas diferentes, termina obstaculizando los caminos hacia el equilibrio. A efectos de dar cuenta de ello, la perspectiva de la Public Choice introduce el instrumental neoclásico al análisis del funcionamiento interno del Estado y muestra con ello, desde la concepción del homus economicus, a los agentes públicos (políticos y burócratas) como sujetos maximizadores, centralmente orientados a la captación de mayores fondos públicos - a expensas de los ciudadanos y el mercado.

Ante este marco analítico, las políticas orientadas hacia la contención del Estado buscan profundizar las reformas basadas en: $a$ ) un desplazamiento del Estado de áreas en las cuales pueden desempeñarse los mecanismos de mercado (mediante privatización, desregulación), y $b$ ) un traslado de dichos mecanismos al interior del Estado (por medio de - entre otras estrategias - una descentralización que promueva la competencia interjurisdiccional).

Sin embargo, existe una manera alternativa de abordar la expansión del Estado que proponemos explorar en su consistencia empírica. La misma ubica el origen del problema fuera de la estructura estatal y lo sitúa en el campo de las relaciones sociales de produc-

11 Lectura convergente con enfoques vernáculos argentinos, como la Fundación de Investigaciones Económicas Latinoamericanas, el Centro de Estudios Macroeconómicos y la Fundación Mediterránea (Fernández, Tealdo y Villalba, 2005).

12 En la cual son centrales los desarrollos teóricos de Tullock (1980) y Brennan Buchanan (1980). 
ción. En esta lectura, el mercado, lejos de ser autoequilibrado, está surcado por contradicciones (propias del sistema capitalista) que trasladan al Estado un imperativo de actuación — también contradictorio - destinado a ocuparse de los costos sociales de la reproducción del capital, así como a subsanar el accionar anárquico de los capitales privados, incapaces de garantizar por sí mismos la continuidad del proceso de acumulación (O’Connor, 1981; Offe, 1991). El Estado, al actuar en las contradicciones operadas en el nivel de las relaciones de producción del sistema capitalista, se convierte en el sostén del proceso de acumulación y, tratando de conjugar la apropiación privada del excedente social con una permanente socialización de los costos, opera en la dinámica de legitimación afectada por la exclusión y dualización generadas desde la acción del mercado. Desde ese enfoque, las reformas estructurales impulsadas desde la plataforma teórica market friendly del BM, al colocar al mercado como el más eficiente distribuidor social, conllevan desde el inicio una demanda de implicación creciente del Estado para atender esos campos de acumulación que no pueden ser sostenidos individualmente por los capitalistas, así como para asistir en el área de legitimación social los efectos dualizadores y excluyentes generados por un mercado incapaz de autorregularse (Polanyi, 1989).

Esta perspectiva, alternativa de aquella de profundización de reformas mercantilizadoras, no obstante haber caído en olvido en las producciones académicas de los últimos quince años, muestra una notable potencialidad para dar cuenta empíricamente de los factores involucrados no sólo en esta inconsistencia de la propuesta del BM en la cual se funda el aumento del tamaño del Estado aun luego de las reformas destinadas a reducirlo, sino también de la demanda de capacidades atada a esta profundización de reformas remercantilizadoras.

\section{La estratégica implicación en el área}

de la acumulación como fundamento del aumento del

tamaño estatal en el ámbito nacional

La implicación estratégica del Estado nacional en el sostenimiento del proceso de acumulación constituye el factor fundamental para explicar por qué, no obstante la profundidad de la reforma privatizadora, desreguladora y descentralizadora que se fue consolidando en Argentina después de 1993, el Estado nacional continuó creciendo durante toda la década.

Sostenidas, como vimos, por los OFI - y entre ellos por el BM-, las reformas remercantilizadoras de inicios de los noventa se insertaron dentro de una estrategia de acumulación orientada a consolidar una reproducción del capital global financiero y productivo. En el primer caso, el proceso de apertura al ingreso-egreso de capitales, sustentado en el referido modelo de convertibilidad — con tipo de cambio sobrevaluado- y altas tasas de interés, alimentó la entrada incontrolada de capital internacional con un objetivo de valoración financiera (Basualdo, 2000). En el campo productivo, el también mencionado proceso de desregulación y privatización se orientó a consolidar una matriz 
altamente concentrada de inversores — crecientemente transnacionales - que tomaron posesión con tasas de rentabilidad asegurada (Azpiazu, 1999).

Ahora bien, el despliegue de esa estrategia, para el posicionamiento selectivo de esos actores, se desarrolló sobre la base de la consolidación de una estructura productiva de escasa complejidad, que veía agravada - y no revertía - esa característica producto del perfil rentista y crecientemente transnacionalizado de las inversiones (Fernández, Tealdo y Villalba, 2005; Chudnovsky y López, 2001). Desde dicho perfil, los actores mostraban escasa disposición a reorientar sus utilidades hacia una estructura productiva crecientemente necesitada de incorporar tecnología y desplegar actividades avanzadas en la cadena de valor, que le permitan insertarse en el ámbito internacional en los sectores más dinámicos.

La — progresiva - debilidad y descomplejización de la estructura productiva y su incapacidad para ingresar activamente en el mercado externo fueron generando un déficit estructural en la capacidad de inyectar divisas que oxigenen el sistema económico y den salud fiscal y financiera a la estrategia. La profundización de esta última y de ese déficit (en un contexto de apoyo de los OFI, cuyas recomendaciones centrales se seguían) demandó a la instancia nacional del Estado una nueva intervención estratégica en el área de acumulación; en este caso, convirtiéndolo en un "agresivo agente de endeudamiento" (Weisbrot y Baker, 2002). Como consecuencia de ello, el pago de intereses del endeudamiento externo (gráficas 2 y 3 ) —y no los factores ligados a la política social o al apoyo al sector productivo- se transformó en el principal factor del crecimiento del gasto público y, por lo tanto, del aumento del tamaño del Estado.

\section{La estratégica implicación en área de la legitimación \\ como fundamento del aumento del tamaño estatal \\ en el ámbito provincial-regional}

En el ámbito provincial se siguió la misma ruta del aumento de tamaño del Estado, como resultado de su creciente involucramiento en el área de actividades vinculadas a la legitimación social. Para comprenderlo mejor, es fundamental tener en cuenta que, dentro

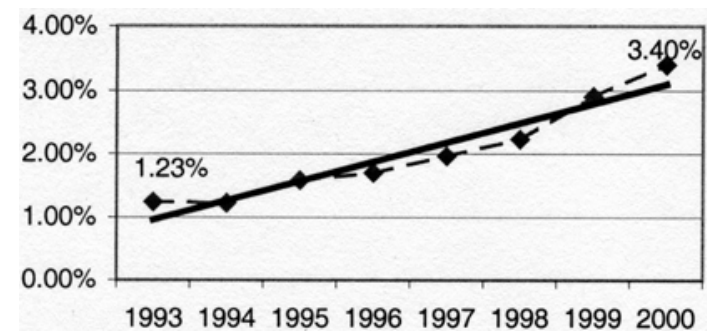

Gráfica 2. Pago de intereses de la deuda como porcentaje del PIB, Argentina, 1993-2000.

Fuente: elaboración propia con base en datos de la Secretaría de Hacienda, MECON. 


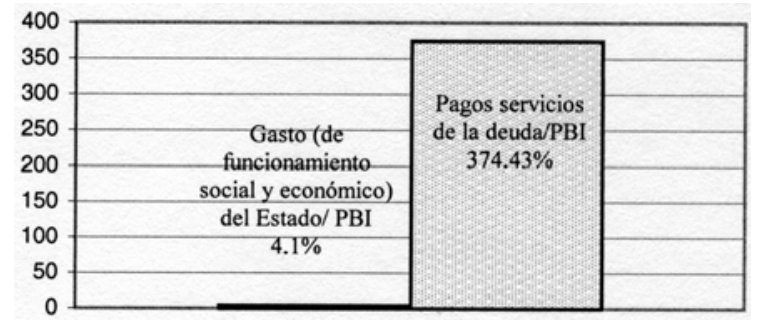

Gráfica 3. Comparación del incremento porcentual del Gasto Público Nacional/PIB 1990/2001, distinguiendo gasto total (sin servicios deuda) y gasto servicios de deuda.

Fuente: elaboración propia con base en datos de la Dirección de Gastos Sociales Consolidados, Secretaría de Política Económica, MECon.

de las agresivas reformas ocurridas desde inicios de los noventa, tuvo lugar un proceso de desconcentración de actividades por el cual se transfirió a los gobiernos provinciales funciones y servicios básicos (educación y salud, principalmente) antes ubicados en el ámbito nacional (wB, 2001), mientras que, con el correr de los años se generaron en este nivel provincial estructuras estatales vinculadas a la atención de necesidades sociales extremas. De ese modo, el proceso de legitimación se concentró en los espacios regionales, adquiriendo los mismos un papel estratégico que explica, en gran medida, el creciente interés de los OFI, principalmente del Banco Mundial, por la correcta y eficiente gestión del Estado provincial (wB, 1991b y 2001).

Ahora bien, no obstante que resultaba lógico esperar que, en forma inmediata a las reformas descentralizadoras, el gasto público provincial experimentara un crecimiento, era igualmente esperable que, a partir del progresivo alineamiento de las provincias a los programas de reformas estructurales y la gestión fiscal eficiente demandada por los ofi y el Estado nacional, dicho gasto se viera finalmente contenido. Sin embargo, creció y lo hizo a un ritmo incluso mayor que en el nivel nacional resultando, por tanto, un constante incremento de la participación del gasto provincial en el total del gasto público (Gráfica 4).

Ante ese contexto de creciente relevancia ganado por los niveles provinciales del Estado, tanto por razones cualitativas (resultado de la delegación de funciones y servicios claves), como cuantitativas (mayor proporción de crecimiento del gasto), enfrentamos nuevamente un claro interrogante: ¿cuáles fueron los motivos de este crecimiento del Estado cuando se esperaba su reducción o, al menos, su contención?

\section{El caso de la provincia de Santa Fe.}

\section{Análisis del impacto en las estructuras estatales} regionales del enfoque del Banco Mundial

Por dos aspectos la provincia de Santa Fe parece pertinente para responder al interrogante planteado: su relevancia económica y su prolijidad fiscal. Santa Fe (ubicada en la región 


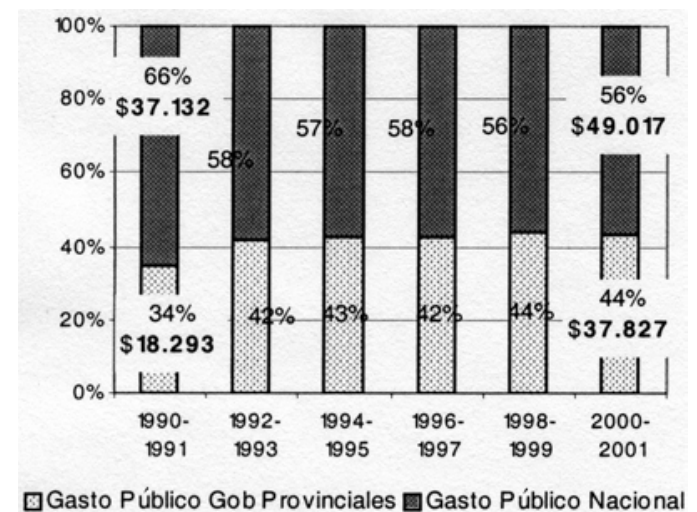

Gráfica 4. Participación del gasto público de los gobiernos provinciales en Gasto Público Nacional, 1990-2001. Fuente: elaboración propia con base en datos de la Secretaría de Política Económica, MECON.

pampeana, la más importante económica y demográficamente de Argentina) se caracteriza por su alta productividad del suelo y gran capacidad exportadora relativa. Junto con Buenos Aires, Córdoba y Mendoza, y sumada la Ciudad Autónoma de Buenos Aires, concentran el grueso de las exportaciones del país $(75 \%)^{13}$ y representan casi $75 \%$ del total de la inversión fija privada en sectores manufactureros. Al igual que esas provincias, posee una dinámica financiera compleja, con fuerte presencia de los principales bancos privados y entidades extranjeras, y con alta participación de los sectores productivos en el total del financiamiento sectorial (PNUD, 2002). Finalmente sumada a ese selecto conjunto de provincias, Santa Fe aporta casi $80 \%$ del PBG total del país, ocupando - junto con Córdobael tercer más grande $\mathrm{PBG}$ provincial. ${ }^{14}$

Desde el punto de vista fiscal, durante los noventa Santa Fe resaltó por ser una administración prudente y ordenada, que compatibilizó con las demandas de eficiencia, austeridad у autonomía provenientes del вм (вм, 1991b). En ese sentido, durante algunos años de esa década la provincia consiguió cubrir con recursos propios hasta dos tercios de sus ingresos. Respecto de los recursos recibidos por coparticipación, esa provincia se mostró entre las jurisdicciones con menos porcentaje de recursos coparticipados afectados a garantía de endeudamiento (menos de $20 \%$ ).

En lo referido a la sanidad y prudencia en el campo del gasto y el endeudamiento, Santa Fe dio cuenta de un sólido posicionamiento en relación con el resto de las provincias argentinas. Sus cuentas fiscales al año 2000 presentaban una deuda sobre ingresos (de $29.7 \%$ ) claramente inferior tanto respecto de las provincias centrales como periféricas, mientras que con un déficit de sólo $3.2 \%$ en relación con sus gastos, quedó también

13 Santa Fe tiene un valor de exportaciones per capita superior en casi $50 \%$ a la media nacional y el peso de sus exportaciones en el PGB provincial supera $20 \%$.

14 La cifra cercana a 8\% del PBG nacional no es menor atendiendo que, después de Mendoza — cuarto lugar-, sólo dos provincias superan $2 \%$ en la participación en el PBG total nacional. 


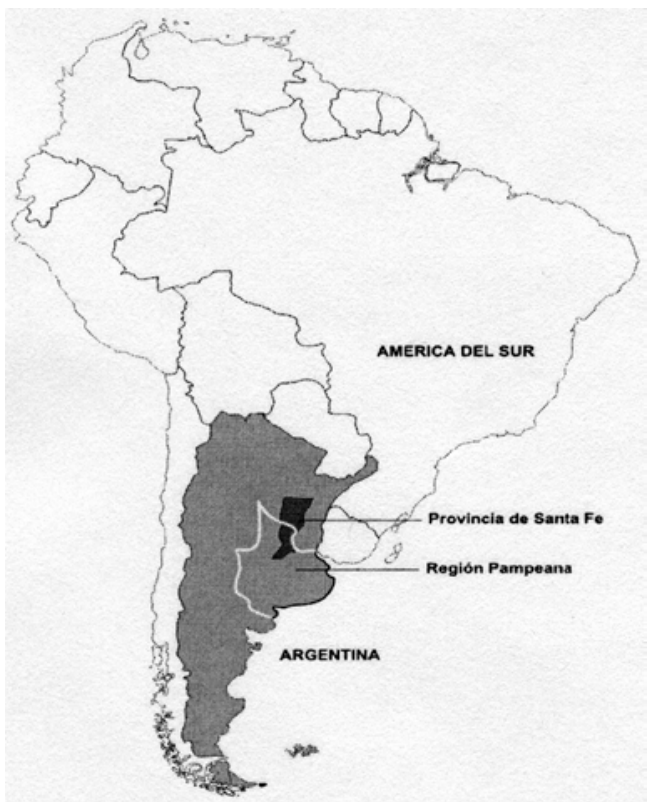

\begin{tabular}{lcc} 
& Cuadro 1 \\
\hline & $\begin{array}{c}\text { Deuda como } \\
\text { \% de ingresos }\end{array}$ & $\begin{array}{c}\text { Déficit como } \\
\text { \% de gastos }\end{array}$ \\
\hline Santa Fe & 29.7 & 3.2 \\
Córdoba & 47.3 & 3 \\
Buenos Aires & 50.5 & 16 \\
La Rioja & 64.4 & 10.9 \\
Entre Ríos & 70.1 & 8.8 \\
Tierra del Fuego & 116.6 & 7.2 \\
Chaco & 138.1 & 13.6 \\
Formosa & 171.9 & 12.6 \\
\hline
\end{tabular}

Fuente: MECON, 2001.

Mapa 1. Localización de la provincia de Santa Fe.

comparadamente en una posición privilegiada. Este perfil de gestión fiscal relativa le otorgó a la provincia y al Estado regional la capacidad para atraer e inducir inversiones de parte del sector empresarial privado local y extrarregional, así como para recibir préstamos de los ofI. Sin embargo, no obstante ese cuidadoso comportamiento fiscal, el gasto público de esa provincia creció y, al igual que el resto de las provincias del país, lejos de operar una reducción, dio lugar a un crecimiento del Estado (Gráfica 5).

Entonces, ¿qué factores aparecen involucrados en el persistente crecimiento del Estado y su gasto público en esta provincia con una solidez fiscal compatible con las reformas estructurales y las demandas del вм?

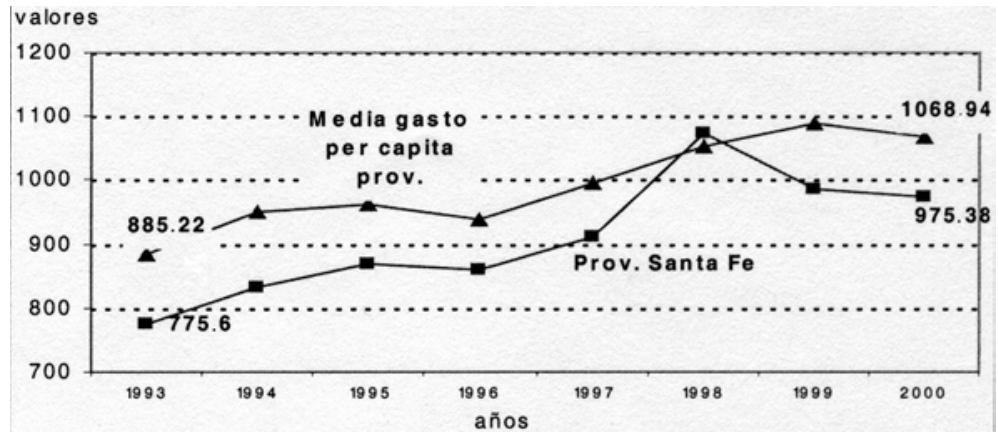

Gráfica 5. Gasto público per capita de la provincia de Santa Fe y media provincial, 1993-2000.

Fuente: elaboración propia con base en datos de la Dirección de Gastos Sociales Consolidados, Secretaría de Política Económica, MECON. 
Efectos sociales en el nivel meso de las políticas

de reforma de los noventa: la espiral de la inconsistencia

Un examen empírico, hecho por medio de la aplicación de los instrumentos teóricoanalíticos pertenecientes a la mirada alternativa que formulamos a la propuesta de profundización de reformas, nos permite ver cómo el nivel provincial quedó comprometido en una atención creciente de las demandas que recayeron en el área de legitimación, producto de los efectos socialmente desestructuradores generados por las reformas estructurales inspiradas en la plataforma market friendly auspiciada por el вм en los noventa.

Los elementos empíricos permiten constatar una espiral conformada como sigue: ajuste estructural basado en patrones market friendly impulsados por el вм $\rightarrow$ efectos de descomposición social: desempleo, precarización y desigualdad $\rightarrow$ aumento de demandas —de bienes públicos - al Estado en el área de legitimación crecientemente atendida por los gobiernos provinciales $\rightarrow$ expansión del gasto público-tamaño del Estado provincial.

La desestructuración social representada en esa secuencia espiralada, la cual operó como antesala de la implicación estatal, puede examinarse mediante dos variables: el creciente desempleo y subempleo, y el constante aumento en la distribución regresiva del ingreso. Efectivamente, acompañando la tendencia de los grandes aglomerados urbanos nacionales $-\mathrm{y}$, por lo tanto, expresando regionalmente lo que sucedía a nivel nacional-, los aglomerados urbanos de la provincia de Santa Fe dieron cuenta de un crecimiento sostenido durante toda la década de los noventa, tanto del desempleo (Gráfica 6) como de la subocupación (que pasó en Santa Fe de $11.4 \%$ en 1990 a $14.6 \%$ en 2000, mientras que en el total de aglomerados urbanos las cifras son, $1990=9.1 \%$; año $2000=13 \%$ ).

Operando con el sedimento de estas dos variables, los mercados de trabajo de Argentina, en general, y Santa Fe, en particular, no quedaron posicionados en forma diferente de los de América Latina durante el periodo examinado; es decir, los países de la región mostraron un mercado laboral que fue profundizando una estructura dual, caracterizada

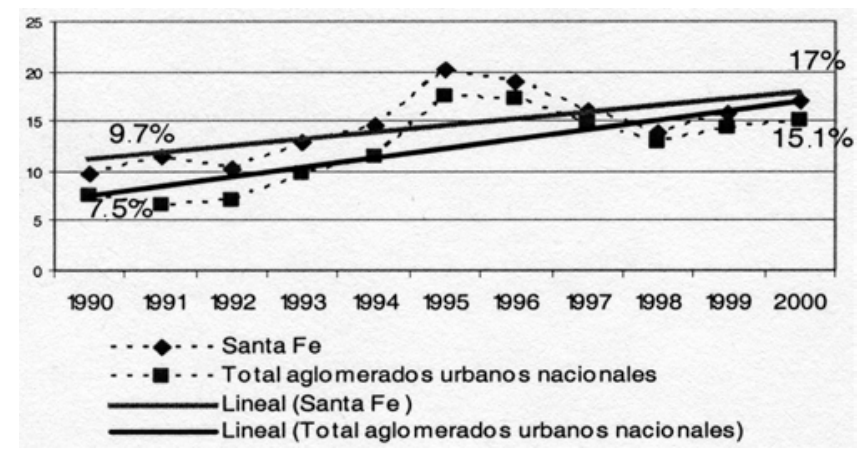

Gráfica 6. Evolución de las tasas de desempleo 1990-2000.

Fuente: elaboración propia con base en datos publicados por el Instituto Nacional de Estadísticas y Censos (INDEC), encuesta permanente de hogares (EPH). 


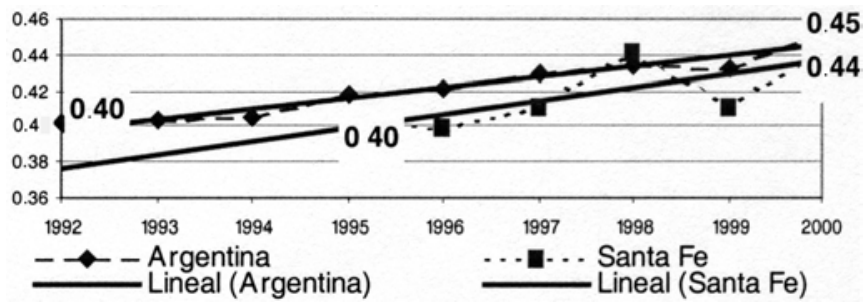

Gráfica 7. Evolución del Indice de desigualdad económica (coeficiente de Gini) para Santa Fe y Argentina 1990-2000.

Fuente: elaboración propia con base en datos publicados por la Universidad Nacional de la Plata, de la EPH.

por la existencia de trabajadores "en negro", que conviven de manera paralela con el trabajador formal, conformando un "proletariado informal" que carece de cobertura social, aportes jubilatorios y demás beneficios legales (Portes y Hoffman, 2003). ${ }^{15}$

En cuanto al análisis empírico de la otra variable, la desigualdad — considerada mediante el coeficiente de Gini- mostró nuevamente, tanto en Santa Fe, como en el caso argentino, que durante los años de la aplicación de las políticas market friendly la brecha entre los ingresos de los estratos superiores y el resto de la población aumentó significativamente (Gráfica 7). Ahora bien, la conjunción de un mercado de trabajo degradado a partir de la expansión del desempleo y la subocupación, junto a la profundización de la tendencia a la redistribución regresiva del ingreso, contribuyeron significativamente a configurar un cuerpo social crecientemente dominado por la exclusión, la marginalidad y la inseguridad social, desde el cual, así como emergieron estrategias heterogéneas de autorreproducción — delincuencia, microempresas de autosubsistencia, emigración(Portes y Hoffman, 2003), se potenciaron las demandas de bienes públicos a las cuales el Estado se vio compelido a responder.

\section{Aumento de las demandas sociales sobre el Estado}

Atento a que las instancias provinciales del Estado fueron asumiendo funciones fundamentales ligadas al área de la legitimación (como la salud y la educación), y estimuladas por los mencionados efectos sociales, dichas instancias se trasformaron en canalizadoras de las demandas de bienes públicos ligadas a esas funciones, como lo refleja claramente la Gráfica 8. El coeficiente de demanda de bienes públicos vinculados a la educación ${ }^{16}$ se potenció a partir de que la población en edad escolar creció $5.7 \%$ en los últimos 10 años, mientras que la matrícula lo hizo $23 \%$. Por su parte, el coeficiente de demanda de bienes

15 En estimaciones calculadas por los autores, el proletariado informal fluctuaba entre un tercio y la mitad de la población empleada en los países latinoamericanos.

16 Total de matrículas en establecimientos oficiales sobre el total de personas en edad escolar (entre cinco y 19 años). 


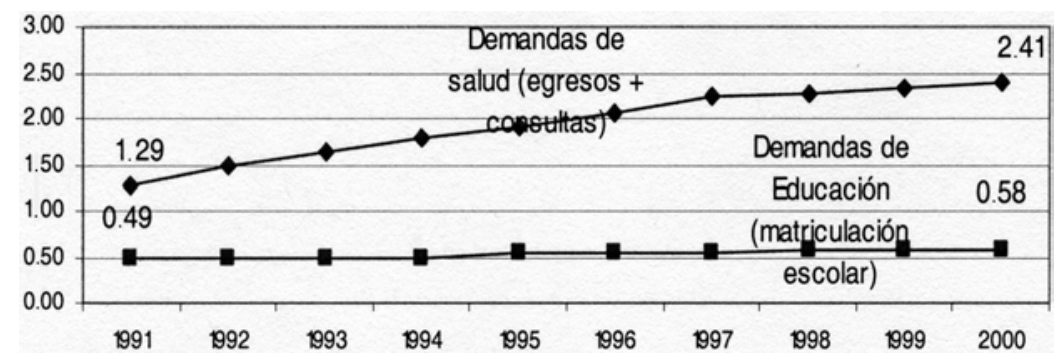

Gráfica 8. Evolución de las demandas de bienes públicos per capita, provincia de Santa Fe, 1990-2000.

Fuente: elaboración propia con base en datos suministrados por los ministerios de Salud Pública y Educación de la provincia de Santa Fe.

públicos vinculados a salud ${ }^{17}$ experimentó un fuerte crecimiento a partir de que mientras la tasa acumulada de crecimiento poblacional para el decenio 1991-2000 fue de 7\%, la de crecimiento de consultas hospitalarias de $84 \%$ y la de egresos en hospitales de $48 \%$.

\section{El área de legitimación como motor del crecimiento irracional}

El análisis secuencial realizado al comportamiento del gasto en la provincia de Santa Fe muestra claramente cómo, al igual que en el ámbito nacional, una provincia económicamente perteneciente al centro rico del país, con una sólida administración fiscal, no pudo frenar las demandas creadas sobre el Estado por el proceso de desestructuración social y el crecimiento de las desigualdades. Al actuar como focos catalizadores de las demandas sociales crecientes, provenientes no sólo del campo de la salud y la educación, sino también de la asistencia social — para lo cual se creó en 1993 la Secretaría de Promoción Comunitaria-, las estructuras del Estado provincial, vinculadas al área de la legitimación social, asumieron progresivamente - a lo largo de los noventa- mayor control en el total de los gastos del Estado provincial (Gráfica 9), convirtiéndose en el principal motor del ya indicado crecimiento estatal. Los datos en tal sentido son elocuentes: las instancias estatales vinculadas a esta área experimentaron una tasa anual promedio de crecimiento de $10 \%$ del gasto a lo largo de los noventa (con un gasto público en 2000 superior en $142 \%$ al de 1991); lo cual contrastó claramente con un escaso aumento de $1 \%$ de la tasa promedio anual de las restantes áreas de gobierno tomadas en su conjunto (2000/1991). ${ }^{18}$

\section{Hacia una mirada sintética acerca de la conformación de la primera inconsistencia}

El examen del caso argentino, así como complementaria y más específicamente el de la provincia de Santa Fe, permite identificar claramente la primera inconsistencia en el posicio-

7 Número de egresos de hospitales públicos y consultas hospitalarias sobre el total de la población santafesina.

18 Se excluyen gastos de las instancias judiciales y legislativas de gobierno, por no ser prioritarias en nuestro análisis. 


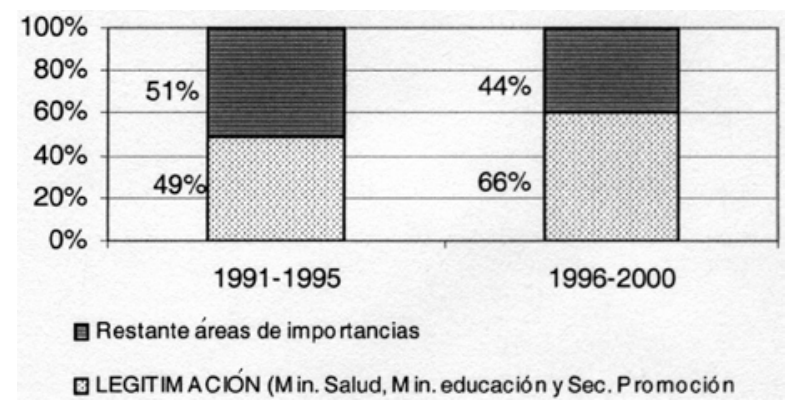

Gráfica 9. Distribución de erogaciones por áreas de la provincia de Santa Fe.

Fuente: elaboración propia utilizando datos de las Cuentas Fiscales de la provincia de Santa Fe.

namiento exhibido por el BM con relación al papel del Estado en el desarrollo. Las políticas públicas de reformas basadas en la plataforma teórica market friendly estimulada por el BM durante los noventa — estructuradas desde el ámbito nacional con el correspondiente alineamiento provincial - tuvieron como efecto directo un progresivo aumento en el tamaño de un Estado al que, paradójicamente, desde aquella plataforma y sus consecuentes políticas, procuraban reducir. La línea de análisis que permite llegar a tal conclusión parte de comprender el comportamiento estatal desde las contradicciones sociales y el creciente - y, por cierto, anárquico - requerimiento de implicación del Estado como resultado de la adjudicación al mercado de una capacidad autorreguladora de la que carece.

Esta inconsistencia tiene un punto de partida: el diagnóstico acerca de los obstáculos al desarrollo que fue depositado casi exclusivamente en el papel sobreinterventor del Estado en las etapas sustitutivas y, a partir de allí, la formulación de una salida fundada en la colocación de los mecanismos mercado como casi exclusivo recomponedor del crecimiento y el desarrollo. Como hemos tratado de mostrar desde el campo empírico, la efectiva implantación de estos mecanismos terminó desnudando no sólo esa incapacidad —y la de los actores capitalistas individuales - de autorregular la reproducción de los nuevos regímenes de acumulación iniciados en los noventa, sino también su clara contribución a un proceso de reconvocatoria - constante y crecientemente estratégica- a la intervención del Estado. Mientras que dicho requerimiento tomó lugar en el ámbito nacional para apuntalar en el área de la acumulación los actores estratégicos del capitalismo global que pugnan por las reformas, en el ámbito provincial - a partir de procesos de transferencia y desconcentración - la intervención se desplegó privilegiadamente en el área de la legitimación social. Un elemento cualitativo nada secundario atado a esta nueva y creciente implicación estatal es que, estimulado para asegurar posiciones en el ámbito nacional (así como en el provincial) a los actores beneficiados con las reformas y a dar respuestas por reflejo para sostener la legitimidad ante el crecimiento de la población excluida y precarizada, el Estado creció - y aumentó su tamaño mediante el gasto- sin responder a una racionalidad planificadora que permita articular la cohesión social con una estructuración institucionalmente ordenada y cualificada. 


\section{La segunda inconsistencia: el reclamo}

de capacidades en los sectores productivos

\section{y el desmantelamiento del área acumulación}

El análisis empírico realizado, junto a la primera inconsistencia, aporta una plataforma adecuada para dar cuenta de la segunda. Dentro del generalizador abordaje hecho por el вм en relación con las capacidades estatales en las reformas de segunda generación, la escueta referencia al papel de las mismas en la producción tuvo que ver con una requisitoria de capacidades previas para impulsar intervenciones estatales complejas en el campo de políticas industriales, así como la necesidad de contar con una efectiva y previa implantación de las reformas de primera generación (privatización-desregulación) como condición para una implicación estatal más activa en ese campo.

El abordaje de la segunda inconsistencia podría realizarse a partir de los siguientes interrogantes: ¿contribuyó esta creciente implicación estatal anteriormente analizada a jerarquizar las capacidades estatales vinculadas al campo productivo? ¿En qué medida, en el contexto de las reformas alineadas con la plataforma teórica market friendly del вм, quedó espacio para fortalecer las estructuras estatales desde las cuales se formulan las políticas productivas e industriales? ¿Qué puede aportarnos —una vez más-el análisis del caso argentino y, en particular, la seleccionada provincia de Santa Fe? Dos aspectos parecen contribuir sustancialmente a encontrar una línea explicativa:

a) Las ideas imperantes sobre las que se estructuraron las políticas públicas - y, por lo tanto, las decisiones de gasto - trabajaron sobre un eje de continuidad formulado desde los OFI, constituido en torno de la pertinencia — y prioridad — de los procesos de remercantilización y a un desplazamiento del Estado del sector productivo-industrial. La sintonización de las reformas con este modelo de ideas tuvo indudablemente un efecto directo en el intento de reducción y marginación de las estructuras y los recursos destinados a las políticas articuladas a este sector.

b) La dinámica generada por dichas políticas dio paso a un constante crecimiento de la implicación estatal fundado en un crecimiento - por lo general anárquico y reflejo- de las estructuras estatales relacionadas con el campo de la legitimación (salud, educación, asistencia social), el cual fue obligando a emplear recursos que podrían haber sido destinados a financiar las áreas vinculadas al sector productivo.

Ambos factores actuaron concatenadamente para transformar las estructuras del Estado vinculadas a la producción en una posición crecientemente marginal. El análisis del gasto, tanto en los niveles nacional como en el provincial — considerando nuevamente de $\mathrm{Santa} \mathrm{Fe}-$, nos permite evaluar empíricamente este proceso de desfinanciamiento de las áreas productivas, el cual refleja la pérdida de relevancia de la acción estatal en este campo, no sólo para impulsar el desarrollo, sino también capacidades institucionales estratégicas. 
A tal fin, dentro de la estructura de recursos/gastos, diferenciamos entre los endógenos -formados por los recursos propios y coparticipados que conforman el presupuesto- y los exógenos - vinculados al financiamiento internacional, con énfasis en los provenientes del BM-, con el objeto de considerar cómo actuaron las estructuras estatales y sus formuladores de políticas y, junto a ello, cómo se implicaron los ofI al momento de conceder financiamiento.

\section{El vaciamiento de recursos destinados}

al área productiva en el ámbito nacional

a) Erogaciones que tienen como fuente recursos endógenos

En el ámbito nacional los datos son contundentes: la ya considerada expansión de los gastos volcados al pago de intereses del endeudamiento externo producida entre $1990 \mathrm{y}$ 2000, acompañada de la estabilización en el volumen de gastos sociales (ante la transferencia de funciones en el nivel provincial), contrastó durante ese periodo con el muy fuerte desfinanciamiento del sector denominado "servicios económicos", en el cual se daba atención a los sectores primario, industrial y servicios (Gráfica 10). Asimismo, dentro del indicado desfinanciamiento a los "servicios económicos", la principal reducción operó sobre el sector — de las políticas—industrial(es) (Gráfica 11), es decir, el sector del Estado al cual, paradójicamente, se le demandaba un fortalecimiento previo de capacidades institucionales (BM, IDM, 1997).

\section{b) Erogaciones que tienen como fuente}

recursos exógenos

Por su parte, el papel de promotores del paradigma teórico dominante, así como la necesidad de asistir al Estado en la consolidación de las reformas emprendidas, contribuyeron evidentemente a que los OFI, y en particular el BM, utilicen similares patrones a los empleados para la asignación de los recursos endógenos en lo que respecta a la marginación de las áreas vinculadas a la producción. Así, si consideramos el financiamiento otorgado tanto por el Bм y el BID entre 1999 y 1997, encontraremos que mientras más de las dos tercercas partes del gasto se destinó a cubrir las reforma del Estado, ${ }^{19}$ sólo 3\% del financiamiento otorgado por estos organismos tuvo como destino directo al sector productivo (Gráfica 12).

19 Vinculadas principalmente al saneamiento financiero y, en menor medida, a gasto social e infraestructura económica. 


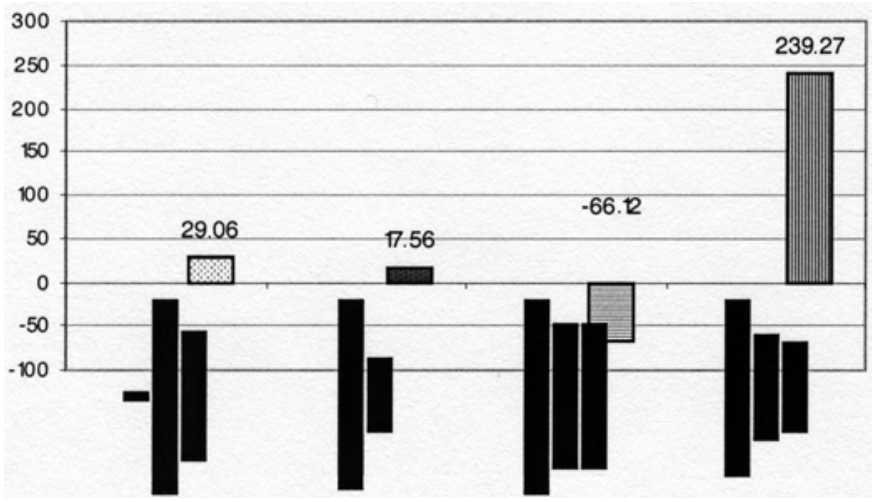

Gráfica 10. Variación porcentual del Gasto Público Nacional/PIB distinguiendo por función (2001/1990).

Referencia:

I. Funcionamiento: Administración General, Justicia y Defensa; II. Gasto Público Social: educación, salud, promoción, trabajo y seguridad social, agua potable y urbanismo y otros; III. Gasto Servicios Económicos: Producción Primaria, Industria, Servicios, otros.

Fuente: elaboración propia con base en datos de Dirección de Gastos Sociales Consolidados, Secretaría de Política Económica.

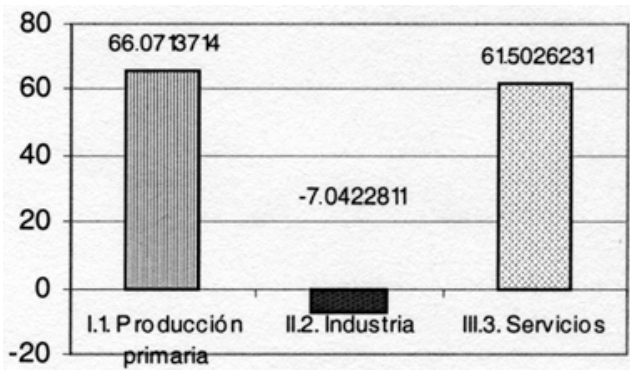

Gráfica 11. Porcentaje de variación 1991-2001 de los rubros de gastos económicos del Gasto Público Nacional/PBI.

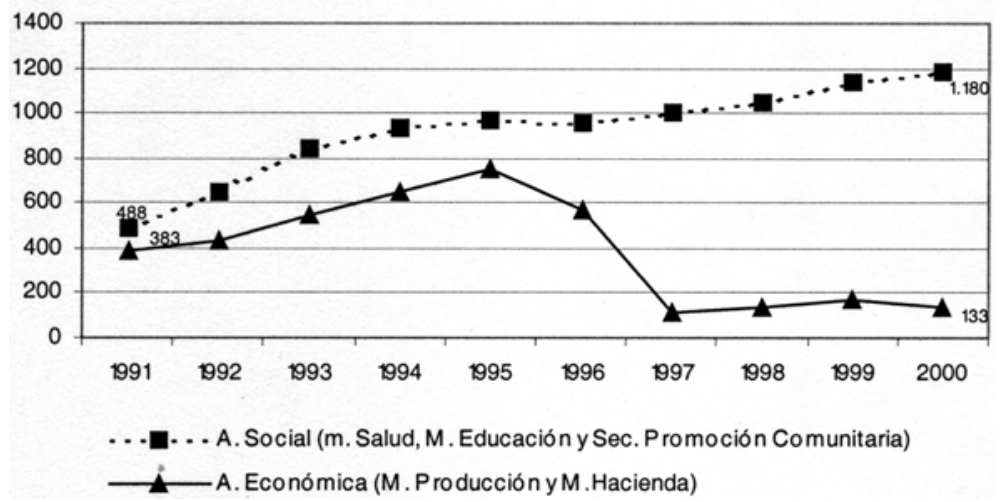

Gráfica 12. Préstamos del BID y del Banco Mundial a la Argentina (total 9408 millones de dólares) 1991-1997. Fuente: elaboración con base en datos de la Secretaría de Programación Económica, MECon. 


\section{El vaciamiento de recursos destinados}

al área productiva en el ámbito provincial

Pero, ¿qué sucede cuando salimos del ámbito nacional y analizamos la estructura/destino del gasto por áreas estatales en el ámbito provincial/regional, donde vimos que el gasto estatal global fue crecientemente relevante? Al retomar la experiencia de Santa Fe, nos encontramos nuevamente con que el gasto endógeno y exógeno asumió un comportamiento claramente convergente con la dinámica nacional.

\section{a) Erogaciones que tienen como fuente recursos endógenos}

La distribución y comportamiento del gasto con recursos endógenos en el periodo analizado permiten ver claramente que en la provincia de Santa Fe el aumento de los gastos vinculados a la legitimación tuvo lugar con un paralelo y muy pronunciado proceso de marginación del área de la acumulación, particularmente en la segunda mitad de la década de los noventa (Gráfica 13). Como resultado de ello, los gastos del área de acumulación, que representaban para 1991 78\% de los gastos del área de legitimación, pasaron a constituir en 2000 sólo 12\%. Por su parte, dentro del área de acumulación, el Ministerio de la Producción (en el cual se formulan las políticas industriales y de desarrollo territorial) participó con un imperceptible 5\%, respecto de 95\% que quedó en manos del Ministerio de Hacienda (donde dominaron prioritariamente las políticas de reforma orientadas al market friendly paradigm) (Gráfica 14).

\section{b)Recursos exógenos (provenientes de créditos internacionales)}

Pero, ¿actuó el financiamiento internacional en ese ámbito provincial con igual orientación que en el nacional, convergiendo con la dinámica de los recursos endógenos? Para responder, primero debemos indicar que, producto de la austeridad y solvencia fiscal

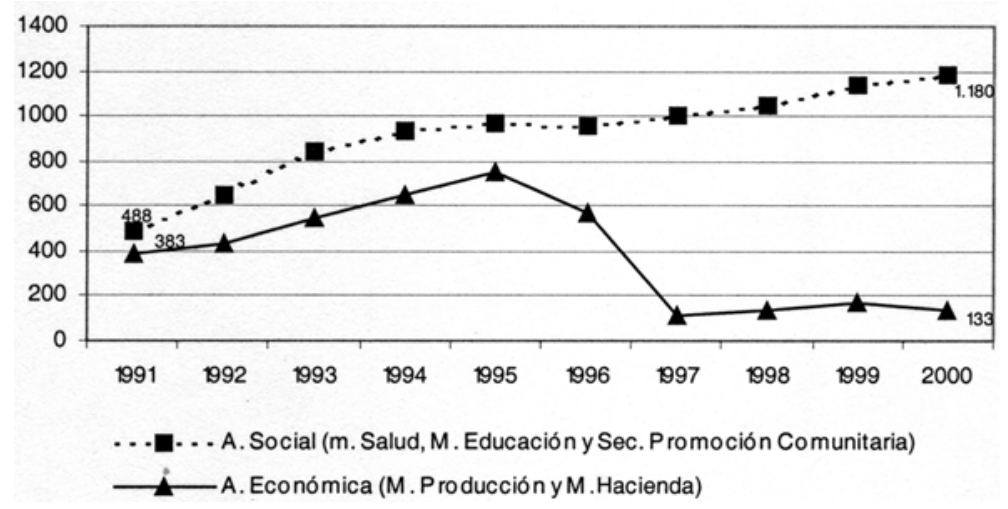

Gráfica 13. Evolución de los gastos totales de la provincia de Santa Fe, según área (1991-2000).

Fuente: elaboración propia con base en datos de la Secretaría de Política Económica. 


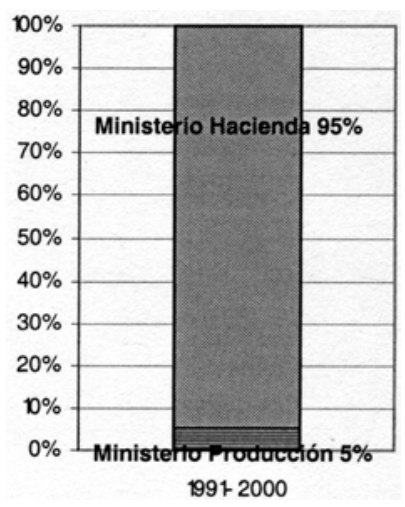

Gráfica 14. Distribución de gastos dentro del área de acumulación, provincia de Santa Fe (1991-2000). Fuente: elaboración propia con base en datos de la Secretaría de Política Económica.

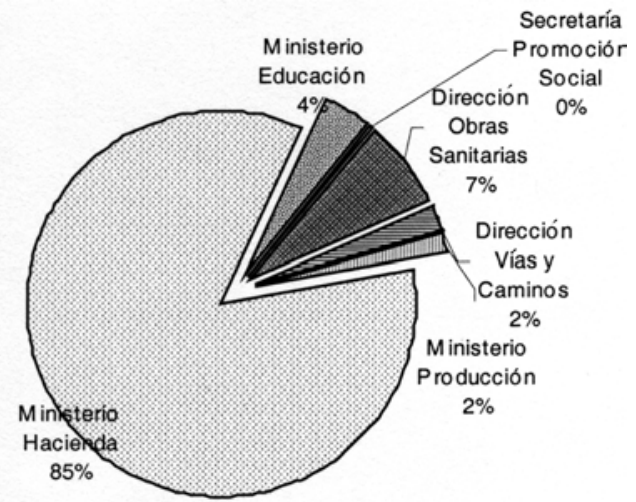

Gráfica 15. Montos totales de créditos tomados por la provincia de Santa Fe distinguidos por organismo tomador (1990-2001).

Fuente: elaboración propia con base en datos de las Cuentas Fiscales, provincia de Santa Fe (Ministerio de Hacienda).

desarrollada en concordancia con las demandas de los OFI, la provincia analizada adquirió a lo largo de toda la década de los noventa una marcada capacidad de endeudamiento con esos organismos y bancos privados externos. El Ministerio de Hacienda (мн) quedó como el estratégico tomador de ese financiamiento, centralizando la negociación y la gestión de hasta $85 \%$ del total de los créditos, lo cual le permitía el alineamiento provincial con las macropolíticas nacionales de remercantilización y austeridad fiscal (Gráfica 15). Aunque ese posicionamiento alcanzado por el MH en relación con el financiamiento exógeno pareciera a priori compensar el escaso oxigenamiento del área de acumulación mediante los recursos endógenos; lo cierto es que un análisis más detenido arroja resultados que van en línea con nuestro planteamiento acerca de las inconsistencias en la formación de capacidades para el ámbito productivo. En primer lugar, esa encumbrada posición tomada por el MH contrasta con la insignificante responsabilidad de endeudamiento asumida por el Mi- 


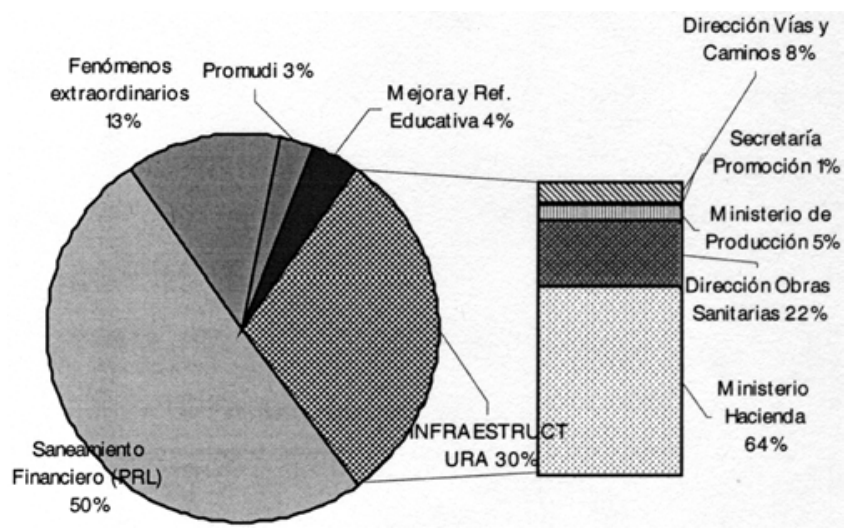

Gráfica 16. Créditos internacionales recibidos por la provincia de Santa Fe distinguidos por finalidad (19902001).

Fuente: elaboración propia con base en datos de las Cuentas Fiscales, Provincia Santa Fe (Ministerio de Hacienda).

nisterio de la Producción, el cual figuró como receptor de sólo $2 \%$ del endeudamiento. Asimismo, cuando analizamos el destino de los préstamos, la información disponible muestra que, mientras no existió a lo largo de la década financiamiento internacional que tuviera como destino el desarrollo institucional o la cobertura de programas vinculados al área productivo-industrial del Estado, nada menos que 50\% de ese financiamiento tuvo como objetivo central el saneamiento financiero y económico de la provincia y la reforma del sector público (Gráfica 16) y, en menor medida, la atención de servicios sociales, como educación y salud. Es decir, el endeudamiento quedó enlazado a aquellas acciones — ligadas a esa plataforma market friendly — seriamente comprometidas en la generación de los efectos sociales que estimularon el crecimiento del Estado en el campo de la legitimación.

Como vemos en la Gráfica 16, del total del financiamiento internacional, $30 \%$ se destinó a la mejora de la infraestructura. ${ }^{20}$ Dentro de este rubro, el MH se posicionó una vez más como instancia privilegiada, controlando y gestionando $64 \%$ de esos fondos, mientras que el Ministerio de la Producción, a cargo de la formulación de las políticas industriales -área a la cual se reclamaba el desarrollo de capacidades como requisito de implantación de políticas de desarrollo industriales (BM, IDM, 1997, capítulo 3)—, participó con un insignificante $5 \%$ de este total.

Por lo tanto, el financiamiento internacional —en el cual se funden voluntades y objetivos de tomadores y dadores de crédito para orientar recursos originalmente exógenos al Estado - muestra una línea de funcionamiento convergente en el desplazamiento del

20 Este rubro abarca los montos destinados a la construcción o mejora de rutas y caminos, la compra de bienes y equipos, el desarrollo de tendidos de agua potable y mejora de barrios, entre otros. 
sector productivo industrial y en la orientación prioritaria de los recursos hacia acciones ligadas a la edificación de la plataforma market friendly (reformas dominadas por el saneamiento financiero), así como hacia las áreas de la legitimación crecientemente demandadas por los efectos sociales generados desde las políticas inspiradas en dicha plataforma.

\section{Hacia una visión condensada de la emergencia y articulación de las inconsistencias}

Mediante el examen del caso argentino, como prototipo de país inspirado en las reformas sugeridas desde Washington, hemos intentado dar cuenta empíricamente de dos inconsistencias fundamentales en la propuesta realizada por el вм en relación con el papel del Estado en el desarrollo a lo largo de los noventa, así como de los factores involucrados en su producción. Con relación a este último aspecto, hemos sugerido que la raíz de dichas inconsistencias debe localizarse en la continuidad mostrada a lo largo de la década por el Bм y los países reformadores que siguieron sus sugerencias de demandar el desplazamiento del Estado del campo productivo-industrial y la remercantilización profunda y acelerada de los procesos económicos e institucionales. Hemos reflejado que los resultados de las reformas privatizadoras y desreguladoras de inicios de los noventa han caminado en dirección opuesta al primer objetivo de reducir el Estado, desarrollando un crecimiento anárquico y, por reflejo del mismo, fundado en dar sostenibilidad al proceso de legitimación político y social ante la creciente desestructuración social (desempleo, precarización y desigualdades) que paradójicamente produjeron dichas reformas.

Hemos, a su vez, dado cuenta que el mantenimiento de dicha continuidad (teórica) y la demanda de una implicación creciente - y por cierto poco cualificada - del Estado en el campo de la legitimación fundó una segunda inconsistencia basada en que ambos aspectos terminaron operando un vaciamiento de las estructuras estatales vinculadas al campo productivo e industrial, a las que el $\mathrm{BM}-\mathrm{y}$ en general los $\mathrm{OFI}$ - pasaron a demandarles un fortalecimiento de sus estructuras y capacidades para concederles el derecho a implicarse en políticas industriales de complejidad.

Siempre sentados sobre el caso argentino —y santafesino—, nuestro último análisis de la dinámica del uso de los recursos tanto endógenos (internos, derivados del presupuesto) como exógenos (financiamiento externo) permite verificar la casi completa desatención de las áreas productivo-industriales, y colocar a la luz la inconsistencia mediante un interrogante: ¿cómo es posible demandar el desarrollo de capacidades en áreas estatales a las que se ha contribuido a desfinanciar para atender casi con exclusividad los objetivos y efectos de las reformas de primera generación?

Ahora bien, verificadas estas inconsistencias, el interrogante pasa a ser: ¿qué relevancia posee la detección teórica y empírica de las mismas en un organismo, como el BM, que asume al desarrollo económico como uno de sus principales objetivos? ¿En qué medida la 
presencia de esas inconsistencias puede haber afectado a los problemas del desarrollo o, si se quiere, a las vinculaciones entre el Estado y desarrollo?

\section{Continuidades e inconsistencias, sus efectos en el desarrollo de la región latinoamericana. Hacia una comparación con las economías del este asiático}

En respuesta a los últimos interrogantes, evaluaremos las consecuencias derivadas de las políticas basadas en esas inconsistencias, a partir del hecho de considerar los comportamientos del desarrollo en aquellos ámbitos en los cuales ganaron lugar los programas de reformas y las políticas públicas inspiradas en la plataforma teórica impulsada desde Washington. Debe indicarse que, más allá de las especificidades nacionales y de la ubicación de Argentina durante los noventa como uno de los más cabales referentes de aquella plataforma teórica, dichas reformas y políticas ganaron lugar en la mayor parte de América Latina (AL) (Bresser Pereira, 2001). Por lo tanto, podemos considerar esas performances desde este nivel regional, desarrollando una perspectiva comparada con aquellas experiencias fundadas en estrategias de desarrollo diferentes de las impulsadas en América Latina desde Washington.

La ya considerada trayectoria del este asiático (EA) aparece como un referente para dicho ejercicio comparativo, dado que, más allá de las discusiones que tuvieron lugar en relación con las mismas, ${ }^{21}$ así como la diferenciación generacional y especificidades de sus esquemas de desarrollo, ${ }^{22}$ la mayor parte de esos países se desplazó claramente de la estrategia presentada por el BM, colocando al Estado no como un epicentro de los problemas que obligaba a su desplazamiento, sino como un instrumento estratégico para el desarrollo de procesos industrializadores con alta competitividad externa. Al pretender colocar las exitosas experiencias asiáticas en línea con su enfoque market friendly (wB, 1993), el BM debió pasar por alto el hecho de que el despegue de las HPAE contó, como aspecto fundante, con un Estado activo y altamente implicado, que actuaba como un catalizador de los procesos económicos y daba cuenta de una gran "capacidad de adaptación” a los cambios que las economías le imponían (Stiglitz, 1996).

21 Las explicaciones del éxito asiático recuerdan a la ya referida discusión del informe del BM sobre el milagro asiático hacia 1993.

22 Sin desconocerse las heterogeneidades nacionales, pueden diferenciarse, básicamente, dos grupos de países del este asiático: el primer núcleo/anillo de desarrollo (Japón, Corea, Taiwán, Singapur y Hong Kong) y el segundo núcleo/anillo de desarrollo del sureste asiático (Tailandia, Malasia e Indonesia). Si bien los primeros - liderados por Japón desde la segunda mitad de los sesentarepresentaron un modelo sociopolítico de organización, con una estructura de actores corporativos y con un Estado disciplinador fuerte, el segundo anillo fue, en términos relativos, menos propicio a recurrir a la acción activa del Estado como lo fuera el primero, aunque fue receptora de muchas de sus herramientas. 
Fundamentalmente en la experiencia de los países del primer anillo de desarrollo fue remarcada la decisión de capitalizar y reforzar la capacidad y autonomía estatal para hacer efectivas y enraizadas redes de cooperación institucional publico-privada sólidas (Evans, 1995; Chang, 2004), desde los cuales combinar - y no incompatibilizar- esquemas sustitutivos de importaciones, tendientes a dar fortalezas a las estructuras productivas industriales internas, con una agresiva inserción en los mercados internacionales, desarrolladas a partir de los rendimientos de los propios actores promocionados (Amsdem, 2004; Hikino-Amsden, 1995; Evans, 1995; Chang, 2004). La combinación de mercados internos fomentados con alta implicación externa conllevó el uso de una amplia panoplia de instrumentos arancelarios, impositivos y de subsidio directo, así como un importante involucramiento de institutos gubernamentales de investigación y desarrollo, destinándose todo ello a potenciar aprendizajes e innovación tanto en la industria básica, como en los sofisticados nichos productivos de la "alta tecnología" (Amsden, 1996 y 2005; Wade, 1990).

Ahora bien, ¿qué resultados arrojaron en términos de desempeño estas estrategias diferentes: la de AL, atada al espíritu market friendly, y la del EA, que colocó al Estado como articulador estratégico de los procesos productivos? Para medirlo, tomamos tres aspectos básicos, ${ }^{23}$ cuya presencia articulada permite una evaluación bastante comprensiva de la dinámica del desarrollo: $a$ ) el crecimiento, $b$ ) el posicionamiento de la región en el contexto de los mercados internacionales, y $c$ ) el grado de cohesión interna logrado.

a) En lo que respecta al crecimiento, las diferencias en el desempeño entre AL y el EA muestran ser de largo aliento: consolidadas en el periodo de sustitución de importaciones desarrollado por ambas regiones desde la posguerra, dichas diferencias parecen haberse profundizado desde fines de los ochenta y a lo largo de los noventa. Así es que, partiendo durante ese periodo de posguerra desde una posición sumamente rezagada, las economías del EA finalizaron el siglo xx con una participación en el PIB de los países de la OCDE similar a la de América Latina (Gráfica 17), a partir de tasas de crecimiento promedio muy superiores a las de esta última región. ${ }^{24}$

Sin embargo, se percibe claramente que en el caso de la experiencia asiática, el largo proceso expansivo de posguerra, sustentado en una sólida base otorgada por las estrategias de desarrollo que articulaban Estado, industria y mercado interno, le permitió mantener durante los noventa su proceso de crecimiento, no obstante las presiones aperturistas y mercantilizadoras provenientes de los sectores financieros internacionales (Wade, 2000;

23 Trabajamos un periodo de largo alcance para evaluar el comportamiento de la década de 1990 —objeto de nuestro estudio- en un contexto más amplio, que permite la comparación diacrónica.

24 A Japón, si bien ha mostrado una desaceleración en la última década y media, su fuerte ritmo de expansión durante las tres décadas siguientes a la posguerra (oscilando entre $6 \%$ y $7 \%$ ) le permitieron cerrar el siglo xx no sólo manteniéndose como una de las economías líderes en los PIB per capita de la OCDE, sino jugando incluso un papel estratégico en la expansión y consolidación operada en el segundo y tercer anillo de las HPAE. 


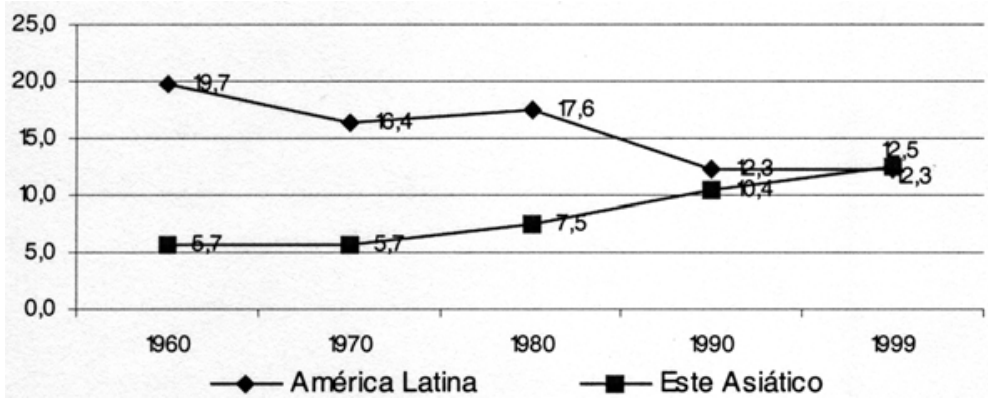

Gráfica 17. Evolución participación porcentual del PIB per capita de América Latina y el este asiático en el producto de países de la ocDE.

América Latina: $\quad$ Argentina, Bolivia, Brasil, Chile, Colombia, Costa Rica, Ecuador, El Salvador, Guatemala, Haití, Honduras, Jamaica, México, Nicaragua, Panamá, Paraguay, Perú, República Dominicana, Trinidad y Tobago, Uruguay, Venezuela.

Este asiático: $\quad$ Hong Kong, Indonesia, Corea, Malasia, Filipinas, Singapur, Taiwán, Tailandia.

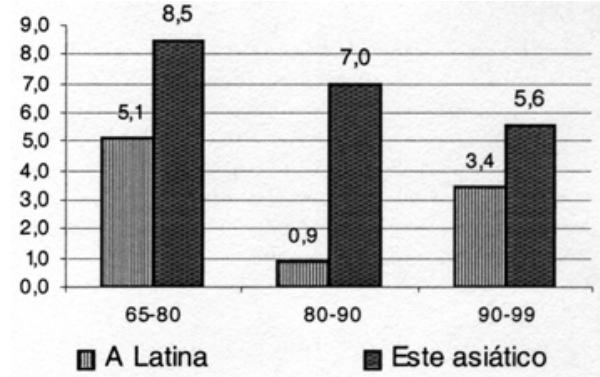

Gráfica 18. PIB-tasa media de crecimiento anual (en \%).

Fuente: $\quad$ elaboración propia con datos de World Bank (1978 y 2000).

América Latina: Argentina, Bolivia, Brasil, Costa Rica, Chile, Ecuador, Colombia, Guatemala, Haití, El Salvador, Honduras, Panamá, Nicaragua, Paraguay, Perú, República Dominicana, Uruguay, Venezuela y México.

Países Asiáticos: Corea, Singapur, Hong Kong, Malasia, Tailandia e Indonesia.

Weiss, 2003). Por el contrario, en el caso latinoamericano, el desplome de su participación en la economía mundial y su abierta pérdida de posiciones en relación con las economías del este asiático tuvieron lugar, especialmente, avanzada la década de los ochenta, con la profundización de la crisis del régimen de sustitución de importaciones, sin que las políticas de los noventa hayan podido manifestar algo parecido a un redespegue (Gráfica 18). En tal sentido, es necesario indicar que el crecimiento de AL durante los noventa, con la introducción de las políticas ligadas a los programas market friendly, tuvo dos características: fue claramente menor que en el periodo de sustitución de importaciones de posguerra (la tasa de crecimiento del PIB per capita entre 1950 y 1980 fue de 2.652, y entre 1991 y 1999 fue de 1.526), y se mostró insostenible en el tiempo, dando cuenta de una marcada caída ya en la segunda parte de esa década (la tasa de crecimiento del PIB per capita 19951999 fue de 0.866) (Morley, 2003). 
b) En lo que respecta a la inserción económica internacional, es inicialmente necesario indicar que en la visión de los defensores de las reformas estructurales desplegadas en AL, el repliegue en la implicación del Estado en el esquema productivo y el paralelo proceso de apertura que permitiría el ingreso de capitales extranjeros — con la consecuente inversión y la incorporación de tecnología - lograría, en primer término, una fuerte modernización de la estructura productiva y, a partir de ello, una sensible mejora en la capacidad de inserción de la región en los mercados internacionales. Sin embargo, a pesar de esa fuerte apuesta al objetivo de la inserción internacional, durante los noventa, en el contexto de un patrón de especialización productiva poco sofisticado y más dependiente, las exportaciones de AL no aumentaron de manera significativa, sino sólo superando muy sensiblemente los valores de años anteriores (Gráfica 19). Por el contrario, fundada en una estrategia de protección del mercado interno combinada con una fuerte orientación a la inserción internacional mediada por el Estado, las exportaciones asiáticas, más altas que las de AL desde la posguerra, continuaron con tasas de crecimiento aun más agresivas que las latinoamericanas (Gráfica 20), que acenturaron las diferencias en desempeño e inserción con AL.

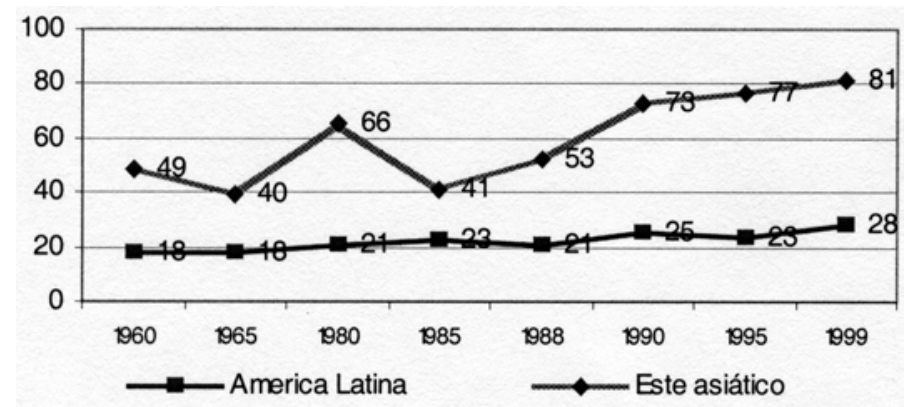

Gráfcia 19. Exportaciones en valores promedio como porcentaje del PIB.

Fuente: $\quad$ elaboración propia con base en datos de World Bank (1984, 1987, 1989, 1990, 1997, 1998, 2000, 2001, 2002).

América Latina: Argentina, Bolivia, Brasil, Chile, Colombia, Costa Rica, Ecuador, El Salvador, Guatemala, Haití, Honduras, México, Panamá, Paraguay, Perú, República Dominicana, Uruguay, Venezuela.

Este asiático: Japón, Corea, Singapur, Hong Kong, Malasia, Tailandia e Indonesia.

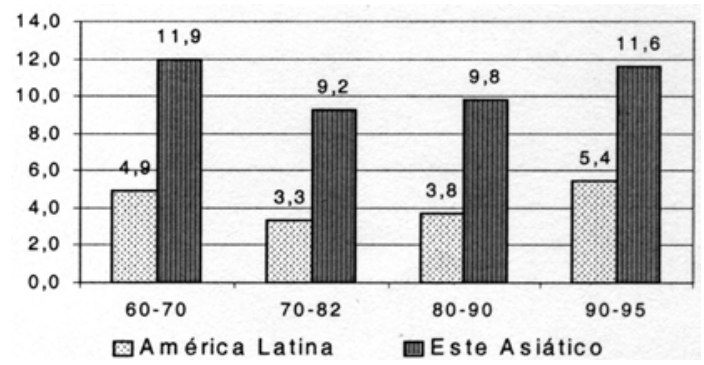

Gráfica 20. Exportaciones, tasa promedio de crecimiento anual.

Fuente: $\quad$ elaboración propia con base en datos del wв (1984, 1987, 1989, 1990, 1997, 1998, 2000, 2001, 2002). 
c) Finalmente, resta analizar los efectos en las estructuras sociales. En línea con el mainstream económico, los impulsores y defensores de las reformas estructurales esperaban que la agresiva introducción de mecanismos de mercado en AL diera paso a un proceso de derrame (trickling down) que potenciara los mecanismos de redistribución y fortaleciera la cohesión interna. Sin embargo, reportes oficiales dieron cuenta de un crecimiento del empleo informal, con una consecuente contracción del empleo formal, en la etapa de ajuste neoliberal, pasando el primero de $44.4 \%$ de la población económicamente activa (PEA) en 1990 a 47.9\% a fines de la década (OIT, 2000). Producto de esa precariedad e incapacidad de generar una dinámica económico-inclusiva mostrada por el mercado de trabajo, no resultó sorprendente el notable aumento de la desigualdad social en la región a lo largo de los años ochenta y los noventa (Gráfica 21), colocándola como la más inequitativa del mundo (Portes y Hoffman, 2003). En contraste, el este asiático — los países del primer anillo- exhibió una constante reducción de dicho coeficiente desde la década de 1970 hasta el fin del siglo xx, mostrando que el exitoso camino de crecimiento e inserción internacional habilitó un colchón para el desarrollo de políticas redistributivas crecientemente demandadas ante la consolidación - especialmente en experiencias como Taiwán y Corea- de sus procesos democráticos (Ramesh, 2003).

Por lo tanto, el análisis por medio de los performances del desarrollo entre ambas regiones otorga elementos para formular una hipótesis, ciertamente profundizable, pero con un razonable sustento empírico: aquellas experiencias, aferradas en líneas generales a la continuidad discursiva del BM, como la latinoamericana de la década de 1990, terminaron, producto de las examinadas inconsistencias, degradando al Estado y perdiéndolo como un actor central en la motorización de una estrategia de desarrollo capaz de combinar la consistencia de sus estructuras sociales y económicas internas con una efectiva inserción internacional. En el exigente contexto marcado por la profundización del proceso globalizador, dicha estrategia, en cambio, ha podido ser llevada adelante por aquellas regiones y países que, tomando distancia de la estrategia market friendly y su continuidad, colocaron al Estado como un instrumento, con altas capacidades institucionales, para for-

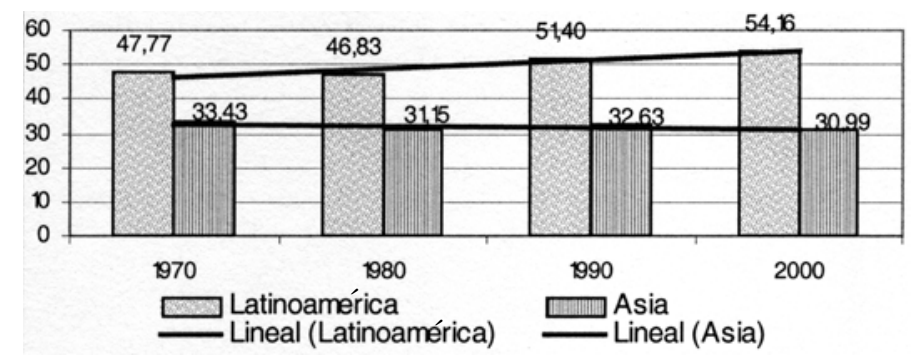

Gráfica 21. Evolución índice de Gini en los tres países centrales de la región latinoamericana y asiática. Fuente: $\quad$ elaboración propia con base en datos del вм, 2005.

América Latina: Argentina, México y Brasil. Asia: Japón, Corea y Taiwán. 
talecer y direccionar la estructura productivo-industrial, orientar la inserción de esta última en los mercados externos y oxigenar la dinámica redistributiva.

\section{Conclusiones: hacia una reasunción endógena de la estatidad en el desarrollo}

Hemos intentado mostrar que la incorporación del Estado y el papel de las instituciones que el вм ha estado realizando a lo largo de los noventa ha requerido de un constante adaptación por parte del organismo para mantener dichas incorporaciones en un marco teórico del desarrollo de matriz neoliberal, que desplaza al Estado de aquellas áreas productivo-industriales en las cuales la experiencia internacional ha mostrado que asume un papel estratégico.

Centrándonos en el caso argentino —alumno ejemplar de las reformas - y en la provincia de Santa $\mathrm{Fe}$ - prototipo de gobierno ajustado a la gestión eficiente requerida por el BM-, mostramos que en la subordinación a ese marco teórico que tiene al mercado como epicentro, las más actuales demandas de calidad institucional y alta capacidad estatal para intervenir en el sistema productivo industrial sostenidas por el organismo han quedado atravesadas por un conjunto de inconsistencias que degradan al Estado mismo. Al momento de traducirse en políticas públicas, dicha degradación contribuye en los países en desarrollo (y en nuestro caso en AL) a ampliar la inhabilidad nacional y regional para motorizar procesos de desarrollo consistentes. Esto último implica la imposibilidad de contar con un Estado involucrado en el fortalecimiento de tramas productivas más complejas, en las cuales se articula un proceso de cohesión social con una efectiva inserción económica internacional en los circuitos más dinámicos y se configura una plataforma efectiva para un crecimiento sostenido.

Ante ello, la posibilidad de encontrar al interior del вм nuevas respuestas que consideren un quiebre de la analizada continuidad y una asunción/admisión de una intervención estratégica del Estado en los procesos productivo-industriales representa no sólo una corrección respecto de los postulados neoclásicos, sino un cambio de magnitud que, incluso, excede el campo de las ideas y se instala en el mundo de los intereses. Efectivamente, ni el capital global — fundamentalmente el financiero — ni los países de matriz anglosajona que hegemonizan la conducción del вм parecen favorecer - y estar dispuestos a encararla generación de estos cambios. De hecho, actualmente, después del informe de 1997, con la adopción de un institucionalismo soft, el Bм desplazó al Estado del centro de la escena, suplantando su tratamiento por un amplio espectro de cuestiones, como la construcción del "buen gobierno", la calidad y la transparencia institucional, el papel del "conocimiento", el combate de la pobreza, entre otros, aspectos que articulan un complejo cuerpo de instituciones (wB, 1998-1999; wB, 1999-2000). 
Sin embargo, desde los países en desarrollo (y los latinoamericanos) la estatidad constituye un desafío tan complejo como ineludible, el cual requiere la construcción consensuada de instituciones endógenas, con alta autonomía, que permitan: a) tomar distancia de la asimilación acrítica de "proyectos uniformes" generados en los países centrales y los organismos internacionales para ser difundidos/replicados en contextos periféricos y disímiles (Evans, 2004); $b$ ) crear un margen de acción nacional y regional ante las crecientes restricciones internacionales generadas desde organismos controlados por los países centrales (Wade, 2003); y, finalmente $c$ ) revertir comportamientos sociales e institucionales —insertos en senderos de dependencia solidificados sobre la base del asistencialismo, el prebendalismo y los juegos particularistas de suma cero- - La posibilidad de materializar esa construcción institucional endógena demanda, paralelamente, la configuración de bases de coalición social amplias y alternativas, así como elites regionales y nacionales compenetradas con la necesidad de visualizar la implicación estratégica del Estado —en sus distintos niveles territoriales - en el área productiva, para cualificar - y no vaciar - la capacidad generadora de valor agregado, desarrollada tanto por medio de las redes como del mercado. ¿Serán nuestros países capaces de articular estos elementos y reemprender una trayectoria que recoloque estratégicamente al Estado en el impulso de procesos productivos y competitivos compatibles con la cohesión social, en el cada vez más agobiante escenario de la globalización que profundiza las divisiones sociales y territoriales?

\section{Bibliografía}

Amsdem, A., "La sustitución de importaciones en las industria de alta tecnología: Prebisch renace en el Asia", en Revista de la CEPAL, núm. 82, Santiago de Chile, abril, 2004, pp. 75-90.

_ , "Why Isn't the Whole World Experimenting with the East Asian Model to Develop? Review of The East Asian Miracle", en World Development, vol. 22, núm. 4, Elsevier, 1994, pp. 627-633.

- Asia's Next Giant: South Korea and Late Industrialization, Nueva York, Oxford University Press, 1989.

__ - "The State and Taiwan's Economic Development", en Peter Evans, Dietrich Rueschemeyer y Theda Skocpol, (editores) Bringing the State Back In, Cambridge, Cambridge University Press, 1985, pp. 78-106. Aoki, M., Information, Incentives and Bargaining in the Japanese Economy, Cambridge, Cambridge University Press, 1988.
Arrighi, G.; B.J. Silver y B. Brewer, "Industrial Convergence, Globalization, and the Persistence of the North-south Divide", en Studies in Comparative International Development, vol. 38, núm. 1, Transaction Publisher, Nueva Brunswick, primavera, 2003, pp. 3-31.

Azpiazu, D., "Las negociaciones contractuales en los servicios públicos. ¿Seguridad jurídica preservación de rentas de privilegios?", en Realidad Económica, núm. 164, IADE, Buenos Aires, junio, 1999, pp. 78-106.

Balassa, B. et al., Development Strategies in SemiIndustrial Economies, Baltimore, Johns Hopking University Press, 1982.

Banco Mundial, Argentina Finanzas Provinciales Actualización IV. Informe Final preparado por Departamento Subregional de Argentina, Chile, Paraguay y Uruguay (Dir Miran Alexander), Washington, octubre, 2001. 
, El Estado en un mundo de transformación. Informe sobre el Desarrollo Mundial, Washington, Oxford University Press, 1997.

, Argentina-From Insolvency to Growth, World Bank country study, Washington, 1993.

_, La tarea acuciante del desarrollo. Informe sobre el desarrollo Mundial, Annual Report, Washington, Oxford University Press, 1991a.

- Argentina, Finanzas de los Gobiernos Provinciales, Washington, Serie de Estudios del BM, Washington, 1991b.

Basualdo, E., Concentración y centralización del capital en la Argentina durante la década del '90. Buenos Aires, Universidad Nacional de Quilmes, FLACSO, IDEP, 2000.

Brennan, R. y J. Buchanan, Analitical Foundation of the Fiscal Constitution, Cambridge, Cambridge University Press, 1980.

Bresser Pereira, L.C., "Reforma de la Nueva Gestión Pública: ahora en la agenda de América Latina, sin embargo...", en International Journal of Polítical Studies, núm. 3, Río de Janeiro, septiembre, 2001, pp.143-166.

Camilleri, J.A. y J. Falk, The End of Sovereignty?, Londres, Aldershot, 1992.

Cavarozzi, M., El capitalismo político tardio y su crisis en América Latina, Buenos Aires, Homo Sapiens, 1996.

Chang, H.J., Rethinking Economic Development, Londres, Anthem Press, 2004.

Chudnovsky, D. y A. López, "La inversión extranjera en la Argentina en los años 1990: tendencias, determinantes e impactos", en Boletín Informativo Techint, núm. 308, Buenos Aires, octubre/ diciembre, 2001.

CLAD, "Reconstruyendo el estado y recuperando su capacidad de gestión. Características y objetivos de la Reforma Gerencial. Una reforma democrática y progresista" (documento), Caracas, 1998.

Cox, R., "Economic Globalization and the Limits to Liberal Democracy", en Mc Grew, The Transformation of Democracy?, Londres, Polity Press, 1997.

Domenicone, H.; R. Gaudio y A. Guibert, "Hacia un Estado Moderno, el Programa de Reforma Administrativa", en Boletín Informativo Techint núm. 269, Buenos Aires, enero-marzo, 1992, pp. 3-28.

Evans, P., "Development as Institutional Change: The Pitfalls of Monocropping and the Potentials of Deliberation", en Studies in Comparative International Development, invierno, vol. 38, núm. 4, Nueva Bruswick, 2004, pp. 30-52.

, "The Eclipse of the State? Reflections on Stateness in an Era of Globalization", en World Politics, núm. 50, Baltimore, Maryland, The Johns Hopkins University Press, octubre, 1997, pp. 62-87.
_- "Government Action, Social Capital and Development: Reviewing the Evidence on Synergy", en World Development, vol. 24, núm. 6, Elsevier, 1996, pp. 1 119-1 132.

- Embedded Autonomy: State and Industrial Transformation, Princeton, Princeton University Press, 1995.

Predation, Embedded Autonomy and Adjustment", en Stephan Haggard and Robert Kaufman (editores), The Politics of Economic Adjustment: International Constraints, Distributive Politics, and the State, Princeton, Princeton University Press, 1992.

Fernández, V.; J. Tealdo y M. Villalba, Industria, Estado y territorio en Argentina de los '90. Evaluando la desimplicación estatal selectiva y repensando los cambios del desarrollo, Santa Fe, Universidad Nacional del Litoral, 2005.

Gatto, F., "Componentes macroeconómicos, sectoriales y microeconómicos para una estrategia nacional de desarrollo.", en Escenarios Alternativos, Buenos Aires, Min. Economía-CEPAL, mayo, 2003.

Hikino, T. y A. Amsden, "La industrialización tardía en perspectiva histórica", en Desarrollo Económico, vol. 35, núm. 137, Buenos Aires, IDES, abril-junio1995, pp. 3-34.

IMF, Inequality, Poverty, and Growth: Cross-Country Evidence, Working Paper núm. 05/28, Middle East and Central Asia Department, prepared by Garbis Iradian, authorized for distribution by J. Erik De Vrijer, Washington, 2005.

Johnson, R., MITI and the Japanese miracle: the growth of industrial policy, 1955-1975, Palo Alto, Stanford University Press, 1982.

Kaplinsky, R. y J. Readman, "How can sme producers serve global markets and sustain income growth?", mimeo, 2001.

Krugman, P., "The Myth of Asia's Miracle", en Foreign Affairs, vol. 73, núm. 6, Nueva York, noviembre/diciembre, 1994, pp. 62-78.

Lal, D., The Poverty of Development Economics, Londres, Institute of Economic Affairs, 1983.

Llach, J., Otro siglo, otra Argentina. Una estrategia para el desarrollo económico y social nacida de la convertibilidad y de su historia, Buenos Aires, Espasa Calpe/Ariel, 1997.

Morley, S., "¿Por qué ha declinado el ritmo del crecimiento económico de América Latina?", en Desarrollo Económico IDES, vol. 42, núm. 166, Buenos Aires, julio-septiembre, 2002, pp. 163-186.

O'Connors, J., La crisis fiscal del Estado, Barcelona, Península, 1981.

Offe, C., Contradicciones en el Estado de bienestar, México, Alianza, 1991.

Ohmae, K., The End of the Nation State, Londres, Harper Collins, 1995. 
Organizacion Internacional del Trabajo (OIT) Panorama laboral: La estructura del empleo urbano en el periodo 1990-1998. Informe de la Oficina Regional de la OIT, www.iolim.org.pe/ panorama/1999.

PNUD, La competitividad de las provincias, Argentina 2002, Aportes para el desarrollo humano, Buenos Aires, 2002.

Polanyi, K., La gran transformación, Crítica del liberalismo económico, Madrid, La Piqueta, 1989.

Portes, A. y K. Hoffman, "La estructura de clases en América Latina: Composición y cambios durante la era Neoliberal", en Desarrollo Económico, vol. 43, núm. 171, Buenos Aires, IDEs, octubrediciembre, 2003, pp. 355-385.

Ramesh, M., "Globalisation and Social Security Expansion in East Asia”, en Linda Weiss, State in the Global Economy. Bringing Domestic Institutions Back In, Cambridge, Cambridge University Press, 2003.

Rojo, P. y A. Canosa, "El programa de desregulación del gobierno argentino", en Boletín Informativo Techint, núm. 269, Buenos Aires, enero-marzo, 1992, pp. 29-45.

Stiglitz, J., "Algunas enseñanzas del milagro del Este asiático", en Desarrollo Económico, núm. 147, vol. 37, Buenos Aires, IDEs, 1997, pp. 323-349.

Strange, S., The Retreat of the State: the Diffusion of Power in the World Economy, Cambridge, Cambridge University Press, 1996.

Tullock, G., "The New Science of Politics", mimeo, 1980.

- The Politics of Bureaucracy, Washington, Public Affairs Press, 1965.

Wade, R., "What Strategy are Vviable for Developing Countries Today? The World Trade Organization and the Shrinking of Development Space", en Review of International Political Economy, vol. 10, núm. 4, 2003, pp.621-644.

, "Governing the Market: a Decade Later", en Working Paper Series, núm. 3, Londres, LSE Development Studies Institute, London School of Economics and Political Science, 2000.

, "Japón, el Banco Mundial y el arte del mantenimiento del paradigma: El milagro del Este asiático en perspectiva política", en Desarrollo
Económico, vol. 37, núm. 147, Buenos Aires, IDES, octubre-diciembre, 1997, pp. 351-387.

, Governing the Market, Princeton, Princeton University Press, 1990.

Weisbrot, M. y D. Baker, “¿Qué sucedió en Argentina?", Paper of Center for Economic and Policy Research, Washington, enero 2002.

Weiss, L., State in the Global Economy. Bringing Domestic Institutions Back in, Cambridge, Cambridge University Press, 2003.

, The Myth of the Powerless State, Nueva York, Cornell University Press, 1998.

World Bank, Public Finance in Development, World Development Report, Washington, Oxford University Press, 1988.

— Attacking Poverty, World Development Report, Washington, Oxford University Press, 2000/2001.

_—_ Entering the 21st Century, World Development Report Washington, Oxford University Press, 1999/2000.

___ Knowledge for Development, World Development Report, Washington, Oxford University Press, 1998/1999.

, From Plan to Market. World Development Report, Washington, Oxford University Press, 1996.

, Workers in an Integrating World, World Development Report, Washington, Oxford University Press, 1995.

$\longrightarrow$, Infrastructure for Development, World Development Report, Washington, Oxford University Press, 1994.

, The East Asian Miracle: Economic Growth and Public Policy, Policy Research Report, Washington, The World Bank, 1993.

, The Challenge of Development. World Development Report, Washington, Oxford University Press, 1991.

, Poverty. World Development Report, Washington, Oxford University Press 1990

, Financial Systems and Development, World Development Report, Washington, Oxford University Press, 1989.

Zysman, J., Government, Markets and Growth, Ithaca, NY, Cornell University Press, 1983. 